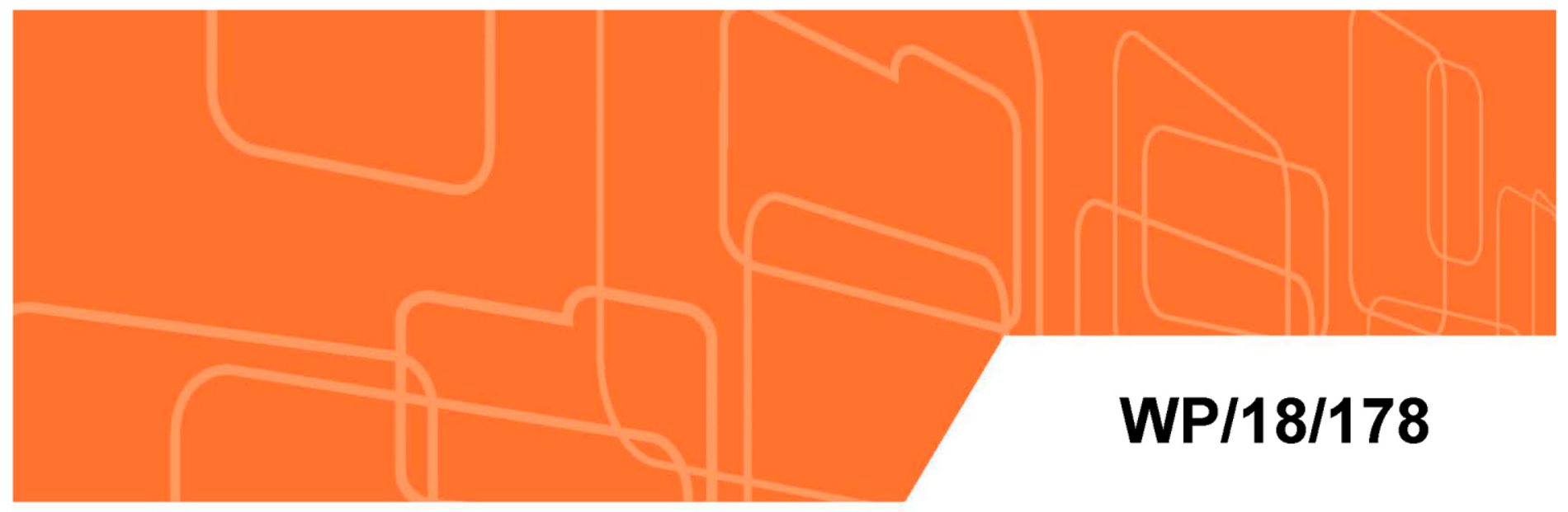

IMF Working Paper

\title{
A Behavioral Approach to Financial Supervision, Regulation, and Central Banking
}

by Ashraf Khan

IMF Working Papers describe research in progress by the author(s) and are published to elicit comments and to encourage debate. The views expressed in IMF Working Papers are those of the author(s) and do not necessarily represent the views of the IMF, its Executive Board, or IMF management. 


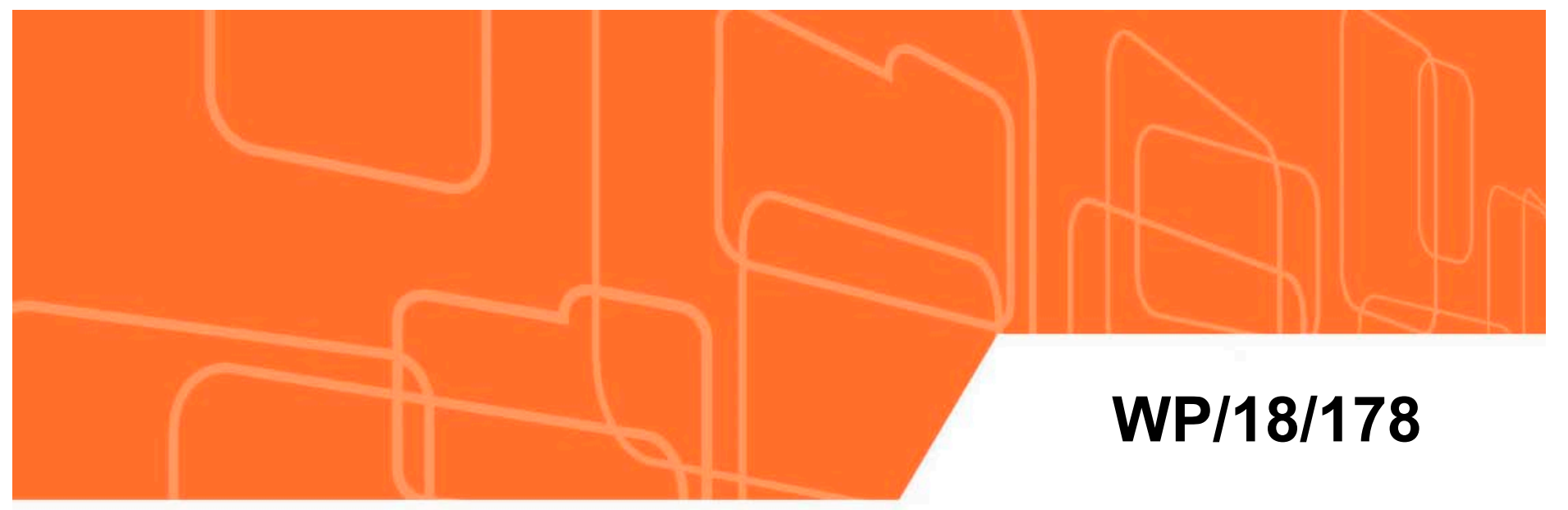

\section{IMF Working Paper}

\section{A Behavioral Approach to Financial Supervision, Regulation, and Central Banking}

by Ashraf Khan

IMF Working Papers describe research in progress by the author(s) and are published to elicit comments and to encourage debate. The views expressed in IMF Working Papers are those of the author(s) and do not necessarily represent the views of the IMF, its Executive Board, or IMF management. 


\title{
IMF Working Paper
}

\author{
Monetary and Capital Markets Department
}

\section{A Behavioral Approach to Financial Supervision, Regulation, and Central Banking ${ }^{1}$ \\ Prepared by Ashraf Khan}

Authorized for distribution by Jihad Alwazir

August 2018

\section{IMF Working Papers describe research in progress by the author(s) and are published to elicit comments and to encourage debate. The views expressed in IMF Working Papers are those of the author(s) and do not necessarily represent the views of the IMF, its Executive Board, or IMF management.}

\begin{abstract}
This paper describes how behavioral elements are relevant to financial supervision, regulation, and central banking. It focuses on (1) behavioral effects of norms (social, legal, and market); (2) behavior of others (internalization, identification, and compliance); and (3) psychological biases. It stresses that financial supervisors, regulators, and central banks have not yet realized the full potential that these behavioral elements hold. To do so, they need to devise a behavioral approach that includes aspects relating to individual and group behavior. The paper provides case examples of experiments with such an approach, including behavioral supervision. Finally, it highlights areas for further research.
\end{abstract}

JEL Classification Numbers: D01, D91, E58, E7, G20, G34, G38, G41, K00, K42, M14, M38, M52, Z10, Z12

Keywords: behavior, culture, financial supervision, financial regulation, risk management, behavioral economics, governance, remuneration, central banking

Author's Email Address: AKhan4@imf.org

\footnotetext{
${ }^{1}$ The author is grateful for comments from Ghiath Shabsigh, Lucyna Gornicka, Deniz Igan, and Prasad Ananthakrishnan. Karen Lee provided invaluable research assistance. Special thanks to Jay Chang and Lilit Makarayan for their relentless focus on excellence in production of the paper. All errors are my own.
} 
Glossary

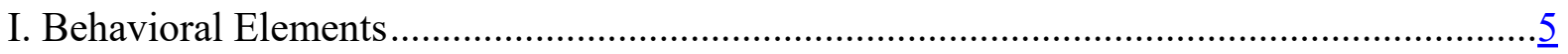

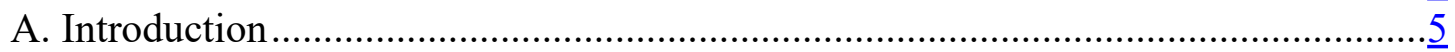

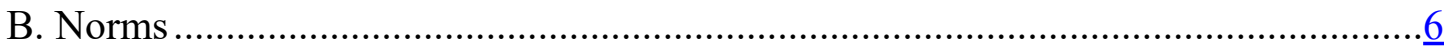

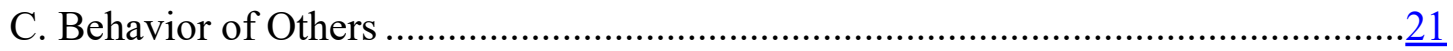

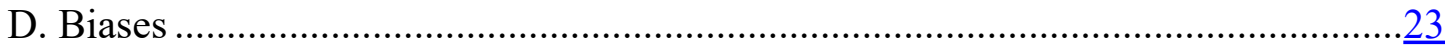

II. Practical Take-Out for Financial Supervisors, Regulators, and Central Banks .................29

A. Framework for Integration of Behavioral Elements into Financial Supervision and

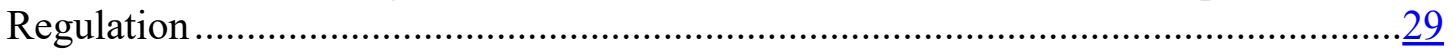

B. An Even Further Enhanced Supervision Mechanism …................................... 43

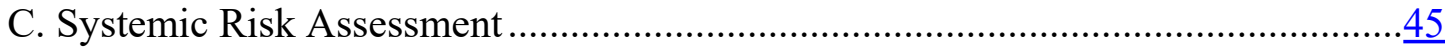

D. Role of Central Banks: Monetary Policy Committees and Communication ........... $\underline{46}$

E. A Behavioral Approach for Financial Supervision, Regulation, and Central

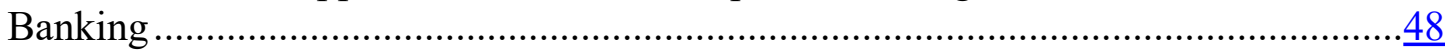

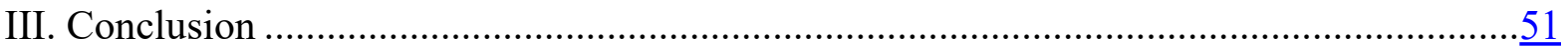

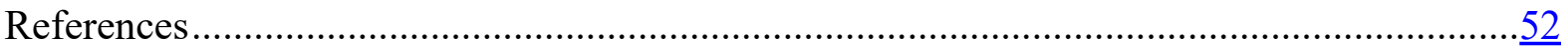

Tables

1. MINDSPACE: Behavioral Elements and Examples ............................................... $\underline{39}$

2. Shefrin's Model for Culture and Governance ........................................................... 41

3. A Behavioral Approach for Financial Supervision, Regulation, and Central Banking ........ $\underline{50}$

Figures

1. Trend in RIA Adoption Across OECD Jurisdictions............................................... 12

2. Legal Norms - Illegal versus Harmful........................................................................ 14

3. Schematic Overview of Agency Theory …........................................................... 17

4.Overview of Biases ........................................................................................

5. Framework for Integration of Behavioral Elements into Financial Supervision and

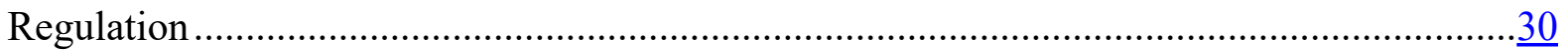

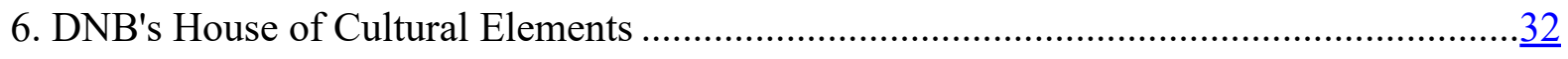

7. Categories and Examples of Supervisory Interventions .............................................44

Boxes

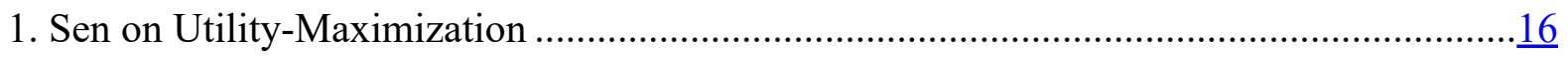

2. Governance - A Matter of Definition .................................................................. 


\section{GLOSSARY}

$\begin{array}{ll}\text { BCBS } & \text { Basel Committee of Banking Supervisors } \\ \text { BIT } & \text { Behavioral Insights Team } \\ \text { BoE } & \text { Bank of England } \\ \text { DNB } & \text { De Nederlandsche Bank } \\ \text { EBA } & \text { European Banking Authority } \\ \text { EC } & \text { European Commission } \\ \text { ECB } & \text { European Central Bank } \\ \text { FSA } & \text { Financial Supervisory Authority } \\ \text { FSB } & \text { Financial Stability Board } \\ \text { GFC } & \text { Global Financial Crisis } \\ \text { IfG } & \text { British Institute for Government } \\ \text { IIF } & \text { Institute of International Finance } \\ \text { IMF } & \text { International Monetary Fund } \\ \text { MINDSPACE } & \text { Messenger, Incentives, Norms, Defaults, Salience, Priming, Affect, } \\ \text { OECD } & \text { Commitments, Ego } \\ \text { RIA } & \text { Organisation for Economic Co-operation and Development }\end{array}$




\section{BehaVioral Elements}

\section{A. Introduction}

Policy responses to the Global Financial Crisis (GFC) were aimed at quantifiable changes to systems, procedures, and rules for the financial sector. Examples are the Basel III capital and liquidity rules for banks to maintain higher standards; the European Solvency II Directive developing similar capital standards for insurance companies; and IFRS 9 (International Financial Reporting Standards) improving accounting rules by making asset and liability valuation more forward looking, incorporating elements of business models and expected losses. These rules were supplemented by further requirements on extensive reporting requirements, and disclosure rules.

The behavioral level of the crisis, however, has only taken a minor role in the policy debate. There has been some attention for behavioral regulatory approaches dealing with the financial sector. Most notable among these efforts are the Financial Stability Board's (FSB) work on risk culture, ${ }^{1}$ the occasional report by the European Commission (EC), ${ }^{2}$ and in the World Bank's World Development Report $2015,{ }^{3}$ but attention for behavioral aspects has not seeped into mainstream economic and financial policymaking.

Some authors note that the GFC has led to a "spike" in applying behavioral research to economic policy "for alternative low-cost approaches to financial services regulation."4 However, more than 10 years after the initial outbreak of the crisis events, the policy response seems not to have included behavioral aspects significantly beyond aspects of corporate governance (for instance, extensive rules on executive compensation, and fit and proper requirements for directors). Some authors note that these governance aspects are predominantly legal rules, quickly drafted during crises. ${ }^{5}$

More extensive, and explicit, behavioral aspects could be derived from insights from other social sciences to benefit the financial sector. "Social science" refers to the academic disciplines concerned with society and human behavior. ${ }^{6}$ This includes economics, sociology, political science, anthropology, psychology, and law. All social sciences examine some aspect of individual decision-making, and therefore behavior.

\footnotetext{
${ }^{1}$ FSB (2014).

${ }^{2}$ European Commission (2013).

${ }^{3}$ World Bank (2015).

${ }^{4}$ Ali, Ramsay, Read (2014), p. 1.

${ }^{5}$ Bainbridge (2011).

${ }^{6}$ Williams (1999).
} 
Economic and legal reasoning in the financial sector is based on seeing individual decisionmaking as part of the homo economicus: Man, who acts out of (conscious) self-interest, and is focused on material incentives. ${ }^{7}$ Instead, this paper links decision-making in the financial sector to those areas of the mind that are emotional and irrational. Decision-making mostly takes place at a subconscious level: ${ }^{8}$ even if there is an awareness of this, it is difficult to understand how much negotiation is possible with hard-wired feelings and emotions. ${ }^{9} 10$

The next subsections look at three categories of behavioral elements: norms (B), behavior of others (C), and biases (D). Next, Section II examines the application of these behavioral elements to the financial sector. Finally, Section III provides concluding thoughts and suggestions.

\section{B. Norms}

Three sets of norms are relevant: social, legal, and market norms. Legal norms are those that are positive law, consisting of written laws, jurisprudence, and case law. Social norms are less tangible ${ }^{11}$, and are part of the realm of values, morals, ethics, and ideas of community. Market norms deal with economic supply and demand - the marketplace where goods and services are offered and sought.

\footnotetext{
${ }^{7}$ World Bank (2015), p. 6, p. 11, and p. 25. See also European Commission (2013), p. 4: “[E]mpirically—and anecdotally — this assumption [of people acting rationally] does not hold. People sometimes make foolish decisions, which are ultimately not in their self-interest."

${ }^{8}$ Neurologist Antonio Damasio (partly countering Descartes) stresses that "somatic markers" (which can roughly be described as "gut feelings") guide us when push comes to shove, and therefore limit the amount of options that we can actually choose from. In that sense, choosing is not an affair of simply the mind, but of subconscious aspects related to our other senses (Damasio, 1996, p. 173).

9 See, e.g., Hauser (2006), who refers to social psychologists Vandello and Cohen when stating that cultural patterns get internalized and are then hardly noted by people themselves, and even "if noted, rarely questioned; if questioned, rarely energetically refuted" (p.154). And similarly, Swaab (2010), referring to fMRI experiments, that show "that there are cortical areas that take seven to ten seconds in preparing a motoric action to prepare before this enters into our consciousness. Experimental interventions have been done to prove that the consciousness lags behind the initiation of the action.... The fact that much of our actions take place unconsciously, does not exclude that we can act consciously when we are drawn to attention" (pp. 385-87).

${ }^{10}$ See the concept of "choice architecture," as described in R. Thaler and C. Sunstein's 2008 Nudge: Improving Decisions about Health, Wealth, and Happiness."

${ }^{11}$ At least, according to natural law lawyers (a positive law lawyer could argue that there is no law other than positive law - the law that exists at a given time). Though this paper does not to give an overview of legal philosophy, it is worth noting that Raz (1983) constructed the well-respected theory of "there is no general obligation to respect the law," as such: "While it is never wrong not to respect the law it is morally wrong to respect it in South Africa [under the Apartheid regime, AK] or other fundamentally iniquitous regions" (pp. 258-59).
} 
Using three categories of norms runs the risk of oversimplifying individual decision-making. It is hard to ascertain which norm (social, legal, market) an individual "chooses" as prevalent in the decision-making process. ${ }^{12}$ Neurobiology ${ }^{13}$ offers some insights, as hundreds of universal behavioral patterns have been listed ${ }^{14}$ (including those relating to dominance and violence across human societies). From this perspective, morality is not seen as a coherent set of ideas, but rather a continuous struggle in our minds, related to areas of emotion, decisionmaking, conflict, social relations, and memory. ${ }^{15}$

Nonetheless, norms influence individual decision-making. This can be a social norm, a market norm, or - overlapping with both the social and market norms - a legal norm. ${ }^{16}$ The choice of norm is mostly not a very conscious one. First, it is often hard to retrace steps in fast mental decision-making processes. ${ }^{17}$ Second, the human mind continuously gives a false sense of being in control, of understanding, if only to provide reassurance that nothing bad is going to happen (see further under "Biases"). There is the risk that any explanations given for moral behavior could be used as self-serving. ${ }^{18}$

\footnotetext{
${ }^{12}$ See also, e.g., Haidt's Social Intuitionist Model of moral judgment, in Haidt, J., 2001, “The Emotional Dog and its Rational Tail: A Social Intuitionist Approach to Moral Judgment," Psychological Review, Vol. 108, No. 4, pp. 814-34. Haidt states that moral judgment is predominantly based on automatic processes (which he calls "moral intuitions") and not on conscious reasoning. Conscious reasoning only comes into play when humans want to find "evidence" for their moral intuitions.

${ }^{13}$ Neurobiology relates to research of cells of the nervous system and the organization of these cells into functional circuits that process information and mediate behavior. It is a subdiscipline of both biology and neuroscience, and can wary from molecular to integrative aspects of the central nervous system. See, e.g., www.sciencedaily.com/terms/neurobiology.htm and https://medicine.yale.edu/neurobiology/.

${ }^{14}$ See Fruehwald (2010), referring to Brown, D.E., 1991, "Human Universals."

15 See Fruehwald (2010). Hauser (2006), p. 60, refers to the "moral faculty": a set of moral principles that are universal and enable rapid judgment on any decision, without our even realizing it.

${ }^{16}$ It is not likely that the social and market norm contexts would overlap. Even in the case of the decision being at the outset in line with both a social norm (say, giving money to a friend in need) and a market norm (giving money to a friend in need with the idea that she will—even if not explicitly agreed — pay you back the same amount or even more later), the underlying rationale will be different.
}

${ }^{17}$ See Kahneman's so-called "System 1," which he uses to describe thoughts that are fast, automatic, frequent, emotional, stereotypic, and subconscious. D. Kahneman (2011), Thinking, Fast and Slow, Farrar, Straus, and Giroux (New York). According to Immanuel Kant, individual introspection is not possible from a scientific point of view, because of lack of reference (and as such, only transcendental arguments are possible: situations in which the mind has no other option but to go about a certain way).

${ }^{18}$ Hauser (2006), p. 74. 


\section{Social Norms}

Social norms are defined here as those norms that govern a society's behaviors and the behavior of individuals in that society, and are internalized through social interaction. ${ }^{19}$ Social norms are felt by people, ${ }^{20}$ can be context related (in Rome, do as the Romans do), and exist without the initial need of putting them down in agreements of any kind. ${ }^{21}$ The World Bank refers to this as "thinking socially": behavior "influenced by social expectations, social recognition, patterns of cooperation, care of in-group members, and social norms. Social norms are not similar world-wide." 22 Etiquette is a good example of a subset of social norms that can differ depending on region, country, or even at a more granular level.

Every social norm can be traced back to a norm routed somewhere in our moral faculty. This is a set of principles that offers guidance to make moral judgments, though it does not determine how to act. ${ }^{23}$ One can refer to morals, moral reasons, ethical questions, and so on; for clarity's sake, this paper refers to social norms including, but not limited to, issues related to morality and ethics.

Social norms are often formalized into legal norms. They have their own standing even if they are not written down in a legal norm, though the legal character enhances compliance with the norm, and/or sanctions non-compliance. This is where social norms and legal norms overlap. ${ }^{24}$ In these cases, the law provides a formalization of social norms by declaring them as standards that need to be followed.

There is an area of social norm adherence that can be considered intrinsic. Complying with a legal norm such as "do not cross at a red light" is acceptable because you think it is "good,"

\footnotetext{
19 See, e.g., Giddens, A., 1984, The constitution of society: Outline of the theory of structuration (Cambridge: Polity Press).

20 See De Waal, F., 2013, The Bonobo and the Atheist (New York: W.W. Norton \& Company, Inc.), who argues that morality is not limited to humans, but is part of nature in general (and therefore also clearly present in animals).

${ }^{21}$ Hauser (2006), p. 105, gives a negative description: "Social norms are rules and standards that limit behavior in the absence of formal laws."

22 The World Bank (2015), p. 7.

${ }^{23}$ Hauser (2006), p. 60.

${ }^{24}$ Raz (1983), p. 245. Examples of these kind of social norms that have been transposed into legal norms are, e.g., prohibition of murder, rape, libel, invasion of privacy, breach of promises under certain conditions, certain kinds of deception.
} 
"what anyone should do," "what is supposed to be done," "normal," "the right thing to do,"25 whether it is because you think it makes traffic safer, or because you see others complying with the norm (see further Section $1 \mathrm{C}$ regarding the behavior of others). This does not mean that (non-)compliance with a social norm is devoid of the influence of incentives. Incentives play a role, but they do so in the actual decision on (non-)compliance, and not so much in the perception of which norm (social, legal, or market) is applicable.

This intrinsic part could be referred to as a sense of moral obligation. The feeling of having to comply is derived from the "nature of values and norms and to the circumstances under which they are learned". ${ }^{26}$ This does not exclude individual preferences, but highlights that norms play an important role. As members of society, a family, or a company, people internalize prevalent norms in those communities. ${ }^{27}$ This link to communities is important, as it raises questions on universal validity. ${ }^{28}$ That is, however, out of scope for this paper. For the financial sector, it is sufficient to note that social norms play a role in individual decisionmaking.

Example: a car driver allows a pedestrian to cross, even though it is not a pedestrian crossing zone. The local legal rules are most likely (a) you must stop at a pedestrian crossing if a pedestrian indicates that he wants to cross and (b) you must not stop on the road where explicitly forbidden and/or when endangering other traffic. Rule (a) does not apply (if it were to apply, stopping would most likely be mere compliance with a legal rule). Rule (b) would only apply if there were a sign indicating that the driver is prohibited from stopping at all times and/or if stopping would endanger others in traffic (for instance, stopping in a bend of the road). Suppose this were not the case. If the driver stopped to let a pedestrian cross (not accidentally an old, frail man with a walking cane), he would do so because "it feels right." The decision the driver must make (to stop or not to stop) is one that is in this case governed by social norms. ${ }^{29}$ Whether the driver decides to stop (and to accept or reject the relevant social norm) depends on other elements (behavior of others, and psychological biases), which will be discussed further on.

\footnotetext{
${ }^{25}$ Stout (2011), p. 6, randomly lists a number of synonyms, e.g., "virtuous, fair, honest, trustworthy, upright, faithful, thoughtful, loyal, selfless, conscientious, generous, caring, kind, agreeable, ethical, decent, praiseworthy, altruistic, humane, charitable, principled, cooperative, considerate, compassionate."

${ }^{26}$ Schwartz (1977), p. 234.

${ }^{27}$ Akerlof (2011), pp. 22, 33.

${ }^{28}$ Hauser (2006), p.131, in describing the Trolley problem, notes that "further, all those who have written on this topic are highly educated, brought up in a Western culture, and over thirty."

${ }^{29}$ One might argue that it is not a norm, but rather it "just makes the driver feel good." That might be the case, but the "good feeling" is still an element of the realm of social norms. As we will see further on, the "feel good factor" might, e.g., be derived from seeing others exhibit this behavior or identifying oneself with somebody who you would think would exhibit this behavior.
} 
Religious norms can be seen, in the context of this paper, as a subset of social norms. A lot of relatively recent research ${ }^{30}$ has been done into the effects of religious beliefs in economic situations and firm performance (see, for instance, Hillary, 2009). ${ }^{31}$ It is not necessary to go into detail on whether religion is of a different (God-given) background, and therefore not on par with the two other contexts (legal norms and market norms), or even on par with other norms in the social context. As mentioned, natural law scholars ascribe a higher order to religious norms than any others, and do not see their conversion into written legal norms as a condition to make them count as norms. What can be stated is that religious norms are embedded in the context of social norms, and linked closely to the way individuals look at groups. (Semi-)religious practices can be used to trigger compliance with underlying social norms in the financial sector.

The Dutch banking oath is an example of such "norm activation" in the financial sector. The oath includes statements such as "I swear that I will endeavor to maintain and promote confidence in the financial sector" and "So help me God." As of 2015, all 80,000 bankers and banking staff in the Netherlands are required to swear to it. Breaking the oath could lead to fines, suspension, or even blacklisting. The oath consists of eight integrity vows, and includes putting clients' interests first and taking care of shareholders. The banking oath has been an initiative of the Dutch Banking Association to assure "ethics must come from within." ${ }^{32}$ Christine Lagarde, the IMF's Managing Director, referred to the oath as a good example of appealing to the moral compass of individuals, while listing the need for the financial sector to "uphold the highest ethical standards." 33

\section{Legal Norms}

Legal norms are mostly an embodiment of state-imposed social or market norms. An example of a social norm is the prohibition of killing someone. In general, through time and

\footnotetext{
${ }^{30}$ The links between religion, culture, and economic development were already promoted in Max Weber's famous work The Protestant Ethic and the Spirit of Capitalism (1905).

31 Who refers to, inter alia, La Porta, Lopez-de-Silanes, Shleifer, Visny (1999) and their use of religion as a proxy for culture in their study of government quality across counties; Stultz, Williamson (2003) and their research into the links between a country's principal religion and the cross-sectional variation in creditor rights; Barro, McCleary (2003) and their research into the correlation between macroeconomic development and church attendance; Guiso, Sapienza, Zingales (2003) and their research into the links between religion and economic attitudes that are conducive to higher per capita income and growth; Iannaccone (1998). Hillary (2009), p. 457. See also Lopez-Claros, A., and V. Perotti, 2014, Does Culture Matter for Development? World Bank Policy Research Working Paper No. 7092.

32 The New York Times, 2014, "With 'So Help Me God' Ethics Oath, Dutch Banks Seek Redemption," December 12, 2014.

${ }^{33}$ C. Lagarde, 2015, The Role of Personal Accountability in Reforming Culture and Behavior in the Financial Services Industry, speech given at the New York Federal Reserve, November 5, 2015.
} 
place, this is seen by most peoples as not acceptable, with some exceptions. Making this social rule ("Thou shall not kill") a legal rule (for instance, drafting a penal code article that prohibits killing with specifically described exceptions) does not change the fact that the rule emerges from a social norm - which subsequently has been made into a legal norm to more clearly mark its boundaries, attach greater value to it, make the penalties clearer, and so on.

An example of the latter (that is, a legalized market norm) is a collective wage agreement. In a perfect demand-meets-supply market, collective wage agreements would be unnecessary (the market would regulate itself); yet these large, binding contracts are drafted to enforce or stabilize a demand-and-supply equilibrium.

The primary function of legal norms lies in preventing and encouraging behavior. This does not automatically imply that behavior is really undesirable for, for instance, the majority of the population. It is discouraged, simply because the law says it should be discouraged. ${ }^{34}$ The other function of legal norms deals with the interaction with social and market norms. This could include either strengthening or weakening the respect given to those norms: giving a legal status to a social norm (do not kill people) or a market norm (minimum wages), makes them sturdier and creates a clarity on what the norm is to all to whom the rule applies.

Legal norms are usually accompanied by sanctions, whether criminal, administrative, or private. Raz (1983) refers to sanctions as "prudential reasons" to comply. From a utilitymaximizing perspective, it therefore would make sense to exhibit compliance behavior, as the decision to not comply would come at a certain cost that presents a loss (or at least a risk to a loss): the costs of sanctions get weighed against the upside of non-compliant behavior. ${ }^{35}$

There are those legal norms of which the underlying norm cannot be traced. Some of these norms can be described as administrative burdens, or red tape. They refer to norms of which the added value is unclear or doubted. A case could be made that this applies to administrative, procedural, and corporate law. However, an administrative legal rule, for instance, that government needs to respond to letters from citizens within a time frame of two weeks is grounded in social norms relating to decent and timely answer and reply. When such administrative legal norms start to seem outdated or irrelevant, it is not because the underlying social norm of "timely answers" is not relevant anymore. On the contrary, the norm can start manifesting itself in other forms. Two weeks might be overly long when smart phone penetration, email and text message usage, and website forms enable much shorter response times.

Impact assessments and cost-benefit analysis are examples of how governments are trying to combat legal norms that are not clearly grounded in social or market norms. Figure 1 below

\footnotetext{
${ }^{34}$ Raz (1983), p. 169.

${ }^{35}$ Raz (1983), p. 242-43.
} 
indicates the number of countries that have requirements for governments to conduct Regulatory Impact Assessments (RIA): "a systemic approach to critically assessing the positive and negative effects of proposed and existing regulations and non-regulatory alternatives". ${ }^{36}$ These negative effects of proposed and existing regulations could consist of extra costs that they entail for subjects (an argument from the realm of market norms), but also confusion they bring about on the possible underlying social norms (that is, is the underlying norm still addressed, or even valid?).

In the US, President Trump issued an Executive Order in 2017 outlining the core principles for regulating the financial system. These principles include "make regulation efficient, effective, and appropriately tailored." 37 Thomas Jefferson hinted at these effects when he said: "State a moral case to a ploughman and a professor. The former will decide it as well, and often better than the latter, because he has not been led astray by artificial rules." 38

\section{Figure 1. Trend in RIA Adoption across OECD Jurisdictions}

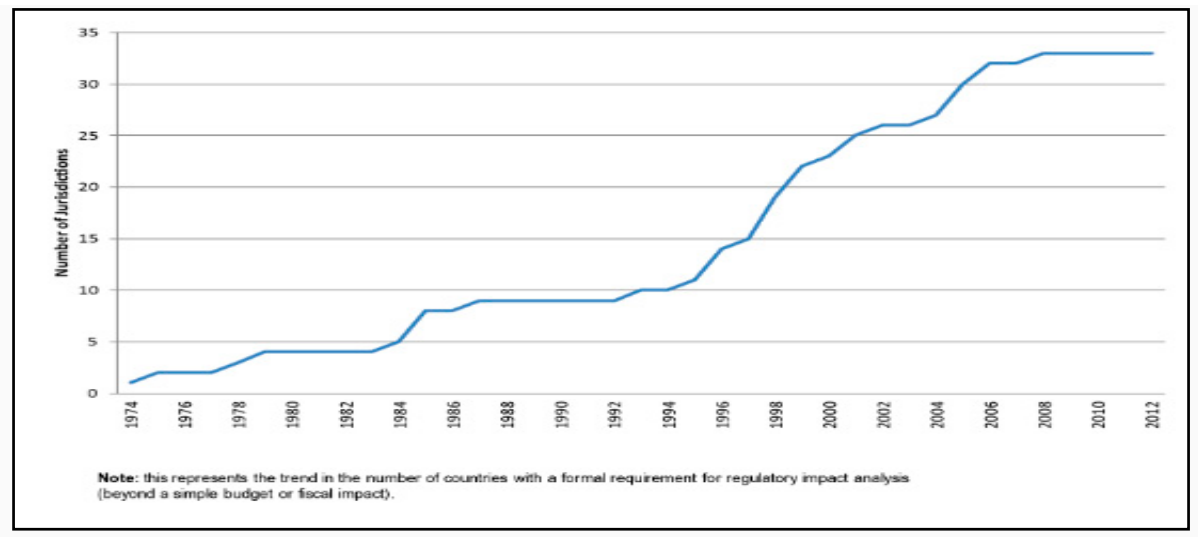

Source: OECD (2012).

A newer trend is combining RIAs with behavioral studies. The EC set up a practice for better European regulation, which includes the possibility of behavioral insights introduced as part of the problem definition: "In Impact Assessment terms, individual behavior can be one of the drivers of a policy problem that a new initiative tries to tackle... This should be reflected in the problem tree, the IA standard illustration of how problems develop and their potential

\footnotetext{
${ }^{36} \mathrm{http}: / /$ www.oecd.org/gov/regulatorypolicy/ria.htm.

${ }^{37}$ President Trump Executive Order 13772, February 3, 2017. According to the US Treasury: "The Administration is pursuing a wide range of coordinated strategies to stimulate growth, including tax reform, a new approach to managing international trade, and improvements to government accountability, including shrinking, where appropriate, the size and role of government. A more efficient system of financial regulation is a critical pillar of policies to stimulate economic growth," in US Department of the Treasury, 2017, A Financial System That Creates Economic Opportunities.
} 
solutions." ${ }^{39}$ This is an example of how policymakers include behavioral knowledge in their practice of policy and rule-making (Section II).

Formalization of legal norms can come with a cost. Braithwaite notes that more formal and complex laws, and the accompanying costly litigation, will likely favor "bureaucratic groups such as corporations. ${ }^{20}$ Some authors have argued that more laws, rules, and regulations could also imply an increase in loopholes, and a diminished sense of responsibility. Rules, in general, have the intention of ascribing responsibility to specific (sets of) subjects. Too (many) specific rules could do the opposite, and contribute to outsourcing that responsibility.

This kind of "creative compliance" 41 could foster the feeling that those issues that have not been dealt with (or have been clearly prohibited) are allowed - even if the consequences clearly harm other individuals. The responsibility for individual actions is placed with the legislator, whose "fault" it is that certain harmful, but not illegal, issues have not been dealt with properly in the law. This, then, leads to the idea that within what is allowed formally no judgment needs to be made on the acceptability of our behavior considering the consequences for others.

A distinction can be made between what the legal norms make illegal and what society considers harmful. Most legislators and regulators aim to make illegal all that is harmful (though, considering the effect of social norms as described earlier, this is not necessarily always the only option). However, Sparrow (2009) highlights that there could also be areas that are not declared illegal by legal norms, but are still harmful, and vice versa: areas that are illegal, but not harmful. The latter is the case of "administrative burdens" mentioned earlier. The former is the case of regulation and legislation being behind the curve: new harmful issues have emerged, but they have not (yet) been addressed by new rules. A supervisor acting on these issues is often characterized as performing unauthorized actions that go beyond the supervisor's mandate / mission creep (Figure 2).

\footnotetext{
${ }^{39} \mathrm{EC}(2013)$, p. 10.

${ }^{40}$ Braithwaite (1995), p. 314, referring to Sutton, A., R. Wild, 1978, "Corporate crime and social structure," in Wilson, P.R., J. Braithwaite (editors), Two Faces of Deviance (Brisbane: University of Queensland Press).

${ }^{41}$ Winter (2010), p. 460. McBarnet (2006), p. 2, in the aftermath of the 2001 Enron scandal, dubbed the behavior of senior Enron staff "creative compliance." She referred to the extensive compliance with mostly very detailed, rule-based regulations, while simultaneously seeking loopholes between those rules. Anything that is not explicitly prohibited is implicitly allowed.
} 


\section{Figure 2. Legal Norms-Illegal versus Harmful}

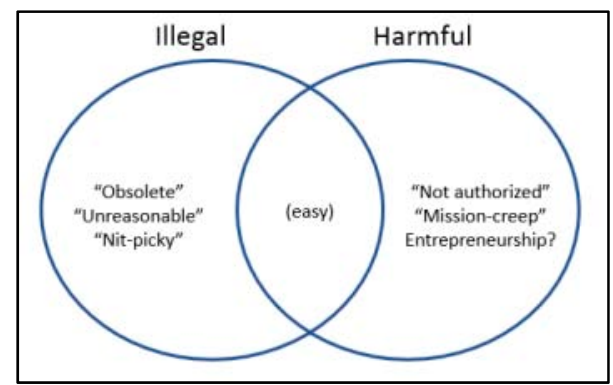

Source: Sparrow (2009).

Some recent research demonstrates that stricter rules lead to "reducing behavior among lawabiding individuals but inducing more law-breaking." 42 In other words: more legal norms could possibly lead to more arbitrage/gaming possibilities and less corporate responsibility.

\section{Rules versus Principles}

This also raises the question of whether legal norms are best captured in rules or principles. Principles are of a broader nature: they set a framework within which there is some form of flexibility in how one can achieve the goal/results set by a standard or principle. The application of standards and principles implies that one has to put in some effort and take responsibility for coming up with a tailor-made solution in order to achieve the goal and results set by the standard or principle. Simultaneously, this requires that the enforcement agency, supervisor, and/or regulator is also able to judge the (in)actions of the subject with a principle-based mindset. ${ }^{43}$

Regulators and supervisors require specific skill sets to deal with principle-based regulation. They will need to be able to judge a broad and varied set of possible applications of a certain

\footnotetext{
${ }^{42}$ In Acemoglu and Jackson (2015), the authors make a distinction between law-abiding citizens and lawbreaking citizens. The authors find that greater fines and better public enforcement both reduces the total number of law-breakers and increases compliance among law-abiding citizens. However, it also increases the level of law-breaking among law-breaking citizens.

${ }^{43}$ A related discussion is that regarding "self-regulation." Self-regulation can be defined as "allowing regulated parties deemed relatively trustworthy to conduct and report their own audits or inspections, subject to some risk of verification" (Sparrow 2000, p. 42, ref. Ayres and Braithwaite 1992 - though arguably this definition holds a narrower compliance scope). Codes of conduct, oaths of allegiance or commitments, solemn statements - they all add an extra "appeal" to a statement that would in general already be considered of the person making the statement (a flag ceremony for new citizens does not imply that people born citizens have any less commitment to their country, nor does it imply (at least, not in most countries) that the new citizens would have any less commitment if they had not partaken in the ceremony). Raz (1983), p. 239: "such an oath may impose a moral obligation to obey (e.g., when voluntarily undertaken prior to assuming an office of state which one is under no compulsion or great pressure to assume). Most people, however, do not commit themselves in this way."
} 
standard or principle, all on their own merit and not always comparable to other applications. Specific training on interview techniques, intercultural awareness, negotiation skills, presentation techniques, and so on, is required. For those who are obliged to comply with the standard or principle, a similar necessity holds. Persuasion, power, and reasoning techniques are needed. This highlights key issues with the enforcement of standards and principles. If the "discussion partners" are not on an equal level of understanding, given the flexibility of the principle or standard, this could lead to unfair outcomes. That is, the company with a strong legal backing would be able to influence an enforcement agency more easily than a one-person business with limited persuasion skills.

The choice between rules and principles is not of an either/or nature. ${ }^{44}$ The English Financial Supervisory Authority (FSA), ${ }^{45}$ for instance, motivated its plea in early (pre-GFC) 2007 for more principles-based regulation by stressing the importance of regulation's ability to respond rapidly to the pace of change in markets. The FSA stressed that "regulation that focuses on outcomes rather than prescription is more likely to support this development and innovation. Any set of prescriptive rules is unable to address changing market circumstances and practices at all times, and it inevitably delays, and in some instances, prevents innovation."

This is supported by research in sectors other than the financial sector. A survey of rules versus principles in the nursing home sector in Australia concluded that when surveyors have an impossible number of rules to check, arbitrary factors will cause particular rules to be met in some homes but neglected in others, causing endemic unreliability. ${ }^{46}$ This has been called the "paradox of discretion": "More and more specific standards are written by lawmakers in the misplaced belief that this narrows the discretion of inspectors. The opposite is the truth: the larger the smorgasbord of standards, the greater the discretion of regulators to pick and choose an enforcement cocktail tailored to meet their own objective. A proliferation of more specific laws is a resource to expand discretion, not a limitation upon it."47

\footnotetext{
44 See, e.g., De Vries (2013), who argues that "[i]n the past two decades, the trend in financial supervisory legislation was to replace detailed rules with more open 'principles.' After the crisis, principles-based regulation was seen as part of the problem and it seemed that is was carried to its grave.... The reality is less clear-cut, however. Financial supervisory legislation, as it stands today, remains a mix of detailed rules and open standards."

${ }^{45}$ Renamed and reorganized into the Prudential Regulatory Authority in 2013.

${ }^{46}$ Braithwaite (1995), p. 321.

${ }^{47}$ Braithwaite (1995), p. 322.
} 


\section{Market Norms}

Market norms are focused on facilitating transactions and contributing to the maximizing of individual utility - the relative satisfaction of the individual. The homo economicus is the strongest subject of market norms, and has been a model for economic thinking for the past 200 years or so. This is where Adam Smith's much quoted line comes into play: that we do not expect our dinner to arise from the butcher's benevolence, but rather from his regard of his own interest. Or, as described more extensively in his Wealth of Nations: An individual: generally, indeed, neither intends to promote the public interest, nor knows how much he is promoting it. By preferring the support of domestic to that of foreign industry, he intends only his own security; and by directing that industry in such a manner as its produce may be of the greatest value, he intends only his own gain, and he is in this, as in many other eases, led by an invisible hand to promote an end which was no part of his intention. Nor is it always the worse for the society that it was no part of it. By pursuing his own interest, he frequently promotes that of the society more effectually than when he really intends to promote it. I have never known much good done by those who affected to trade for the public good. ${ }^{48}$

Box 1. Sen on Utility Maximization
"The reduction of man to a self-seeking animal depends in
this approach on careful definition. If you are observed to
choose $x$ rejecting $y$, you are declared to have 'revealed' a
preference for $x$ over $y$. Your personal utility is then
defined as simply a numerical representation of this
'preference,' assigning a higher utility to a 'preferred'
alternative. With this set of definitions you can hardly
escape maximizing your own utility, except through
inconsistency. Of course, if you choose $x$ and reject $y$ on
one occasion and then promptly proceed to do the exact
opposite, you can prevent the revealed preference theorist
from assigning a preference ordering to you, thereby
restraining him from stamping a utility function on you
which you must be seen to be maximizing. He will then
have to conclude that either you are inconsistent or your
preferences are changing. You can frustrate the revealed-
preference theorist through more sophisticated
inconsistencies as well. But if you are consistent, then no
matter whether you are a single-minded egoist or a raving
altruist or a class conscious militant, you will appear to be
maximizing your own utility in this enchanted world of
definitions. Borrowing from the terminology used in
connection with taxation, if the Arrow-Hahn justification
of the assumption of egoism amounts to an avoidance of
the issue, the revealed preference approach looks more like
a robust piece of evasion....
The complex psychological issues underlying choice have
recently been forcefully brought out by a number of
penetrating studies dealing with consumer decisions and
production activities. It is very much an open question as
to whether these behavioral characteristics can be at all
captured within the formal limits of consistent choice on
which the welfare-maximization approach depends."
Sen, A., 1977, "Rational Fools: A Critique of the
Behavioral Foundations of Economic Theory," in
Philosophy and Public Affairs, Vol. 6, No. 4 , pp. $323-24$.

${ }^{48}$ Smith, A., 1776, An Inquiry into the Nature and Causes of the Wealth of Nations, W. Strahan, T. Cadell (London). 
The concept of the homo economicus lies at the heart of the larger part of contemporary financial regulation and supervision. In addition to Smith's much quoted line of 250 years ago, Alan Greenspan, former chair of the US Federal Reserve's Board of Governors, is often quoted to have said regarding the financial crisis: "Those of us who have looked to the selfinterest of lending institutions to protect shareholders' equity (myself especially) are in a state of shocked disbelief." 49

Another guiding aspect of market norms is that the market, the total supply and demand of goods and services, will find its balance. It is up to the government to tackle potential hurdles in realizing this balance. There are no direct social causes or consequences to this chain of events.

Critique on this limited way of looking at human behavior in economics is not new. In 1977, Amartya Sen expressed doubts on utility-maximization as a proper way to capture human behavioral patterns. Box 1 provides his articulated thoughts on how economists try to capture human decision-making, always bringing it back to utility maximization.

In economic reasoning, Agency theory plays an essential role. First defined by Jensen and Meckling, ${ }^{50}$ it stresses that the interests of shareholders can be different from the interests of managers of a firm, that information asymmetries (the shareholder is not there every time the manager makes a decision) can be disadvantageous to the interests of the shareholders.

Therefore, performance structures should be in place to apply the correct incentives, allowing the actions of the managers to be aligned with the interests of the shareholders (Figure 3 ).

\section{Figure 3. Schematic Overview of Agency Theory}

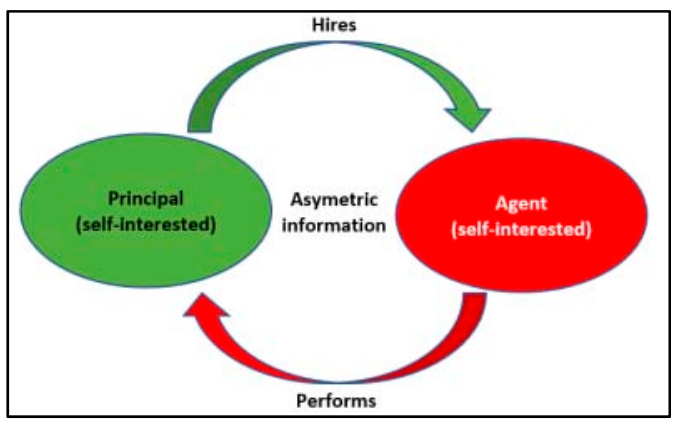

Source: Author.

\footnotetext{
49 Testimony by Alan Greenspan, US House Oversight and Government Reform Committee hearing, October 23, 2008, http:/www.gpo.gov/fdsys/pkg/CHRG-110hhrg55764/html/CHRG-110hhrg55764.htm.

50 Jensen (1976).
} 
Stewardship theory, on the other hand, argues that managers take it upon themselves to act as stewards, serving the interests of the company (and therefore the interests of the shareholders and other stakeholders), without giving preference to their own self-interests. ${ }^{51}$ Akerlof and Kranton $^{52}$ do not use the term "stewardship," but refer to the same sharing of norms when they point out that "the most important consideration in incentives for executives could be their role as fiduciary. Office holders should fulfill the duties of their office. If jobholders have only monetary rewards and only economic goals, they will game the system insofar as they can get away with it. But insofar [as] workers are insiders with the same goals as their organization, such conflict of interest disappears."

Agency and stewardship theories can complement each other. A manager would use social or market norms to guide his/her individual decision-making. For social norms to come into play, it would be necessary for the manager to link the decision he/she needs to make to an intrinsically embedded norm, rather than based on self-serving, utility-focused interest. If money were added to the decision-making process, market norms would guide the decision. ${ }^{53}$ Market norms supposedly could distort a sense of morality. Situations where individuals are faced with a direct personal, financial benefit that is contrary to social norms might incentivize self-serving behavior. An example is that of the worker taking a pen from the office home. He/she would likely come up with arguments such as: "A pen doesn't cost much for my employer," "I will use it to write work-related papers at home as well," "I think other people have done this." ${ }^{54}$ The key way for managers to operate as stewards rather than agents is to create an environment that appeals to social rather than market norms.

Corporate performance-based pay likely makes it more difficult for people making decisions based on social norms. Since the start of the GFC, an increasing field of research shows that monetary incentives seem to have a "crowding out" effect. ${ }^{55}$ The intrinsic motivation of

\footnotetext{
${ }^{51}$ See Davis, J.H., F.D. Schoorman, L. Donaldson, 1997, “Toward a Stewardship Theory of Management," The Academy of Management Review, Vol. 22, No. 1.

52 Akerlof (2011), p. 59.

${ }^{53}$ See Ariely (2010) and Ostrom (in Gintis [2005, p. 264]), referring to Frey and Benz (2001, pp.19-20) on economic incentives: "The economic incentive in itself changes the frame of the exchange relationship across treatments. Over and above the relative price effect they produce, incentives undermine part of the underlying intrinsic motivation by transforming a relational contract into a purely transactional contract (...) Individuals lower their intrinsic efforts in the dimensions where they have the leeway to do so, i.e., in those areas where they do not face the countervailing relative price effect provided by the incentive mechanism."

54 Ariely (2010), p. 291.

55 "Crowding out" here refers to "an undermining effect of rewards and its definition extended to any effect that is opposite to the relative price effect of standard economic theory, whereby reduced costs should increase behavior, and increased costs should reduce it. The effect, therefore, includes cases where penalties increase behavior, and focuses on behavior concurrent with the incentive rather than after its removal." (Promberger, 2013).
} 
people to do a certain task well is distorted by monetary incentives. This in turn often leads to a lower performance than when there are no monetary incentives (see footnote 53 above). Some research highlights that in economic relations, this effect is not as strong as in more pro-social environments, though this is not conclusive.

One explanation for crowding out is that without performance-based monetary incentives, people see their tasks as based in the realm of social norms (more specifically, those relating to cooperation and reciprocity). Introducing an incentive such as money takes the tasks out of the social context and places them into the market context. ${ }^{56}$ For policymakers, these insights are relevant, as they could be used to trigger either social norms or market norms as the prevalent norm context, thus activating specific norms.

This is the concept of norm activation. ${ }^{57}$ It indicates that there are two conditions required for a person to activate an internalized norm (see also next section on internalization):

1) $\mathrm{He} / \mathrm{she}$ has to realize that his/her own actions have an effect on society (awareness of consequences); and

2) He/she must feel responsibility to take action.

Examples of norm activation can be found in recent studies. See, for instance, Ariely (2010): " $[$ W] $[$ hen we are removed from any benchmarks of ethical thought, we tend to stray into dishonesty. But if we are reminded of morality at the moment we are tempted, then we are much more likely to be honest." See also Davidson and Stevens: "We find evidence that a code of ethics only improves manager behavior and investor confidence when the code includes a certification choice, and this effect occurs by increasing moral reasoning in the manager." 59 This is closely linked to what is mentioned earlier on religion and social norms: a banking oath, a code of conduct, and core corporate values - they all are means of activation of (presupposed) intrinsic norms.

\section{A Positive Model of Integrity ${ }^{60}$}

Erhard, Jensen, and Zaffron's Positive Model of Integrity also hints at the difference between market and social norms, where "integrity" is neither good nor bad, and leads to "workability." With integrity not having any association with good or bad, it simply refers to a state of wholeness (keeping your word "whole and complete"). Which, when applied to

\footnotetext{
${ }^{56}$ Winter (2011), p. 4.

${ }^{57}$ Originally formulated by Schwartz (1977).

${ }^{58}$ Ariely (2010), p. 289.

${ }^{59}$ Ariely (2010), p. 28.

${ }^{60}$ Erhard (2008).
} 
individual human behavior, means that a person honors one's word (or "as soon as you know that you will not, you say that you will not and clean up any mess you caused by not keeping your word"). This on its turns leads to workability, which the Erhard, Jensen, and Zaffron define as "the state or condition that determines the available opportunity for performance."

The positive model of integrity distinguishes morality, ethics, and legality, which have normative content. That is, they are about what is right or wrong, good or bad. The authors use the following definitions:

- Morality (social virtue): the generally accepted standards of what is desirable and undesirable; of right and wrong conduct; and what is considered good behavior and what is considered bad behavior of a person, group, or entity in a given society, in a given era of that society.

- Ethics (group virtue): the agreed-on standards in a given group of what is desirable and undesirable; of right and wrong conduct; of what is considered by that group as good and bad behavior of a person, subgroup, or entity that is a member of the group, and may include defined bases for discipline, including exclusion.

- Legality (governmental virtue): the system of laws and regulations of right and wrong behavior that is enforceable by the state through the exercise of its policing powers and judicial process, with the threat and use of penalties, including its monopoly on the right to use physical violence."

In the positive model of integrity, a cost-benefit (that is, market norms) analysis automatically indicates untrustworthiness, as integrity cannot come at a calculated price. Combining a decision on integrity with a cost-benefit analysis of whether you would honor your word guarantees that you will be untrustworthy. Basically, applying the rationale of market norms (by means of a cost-benefit analysis) would take the relationship out of the social context and into the market context.

The Positive Model of Integrity overlaps with social norms. Morality and ethics are part of social norms. Legality is part of social norms as well, but only to the extent that it overlaps with the underlying social norm (on what is right or wrong). The Positive Model's definition of integrity, however, as it is devoid of norms, would seem to add a separate "non-norm context." If integrity leads to workability/opportunities for performance, it becomes a shell: any decision-making on whether to follow a rule can only lead to workability (that is, creating the opportunities for performance) when it is embedded in the underlying thought of being whole. This wholeness would mean that once a norm is being applied in the thought process on whether to follow a rule, deviation from it breaks the integrity. This stresses that switching between social and market norms cannot be done without having unintended effects on others and their behavior. 
In addition to the (social, legal, or market) norm, individual decision-making can be influenced by (perceived) behavior of others.

\section{Behavior of Others}

There are three forms of how the behavior of others influences individual behavior can be distinguished. These are (1) internalization, (2) identification, and (3) conformity. The main difference between these is the level of "intrinsicness": how much of the norm is experienced as "feeling right on its own" rather than because of an external reason (even though that external reason might be an intrinsic one itself). ${ }^{61}$

\section{Internalization}

Internalization can be defined as subscribing to a norm that (regardless of whether it may or may not have been imposed by others) would be described by a person as an intrinsic norm, a norm that "feels as if it is my own." It is the content of the norm that matters for the person acting upon it, not so much the how or when the norm was imposed (or by whom). Ariely refers to Sigmund Freud, saying that as we grow up in society and witness the behavior of others around us, society's social virtues get internalized by us. This leads to the development of something called the "superego." This superego stimulates us to comply with those social virtues. However, this "internal honesty monitor is active only when we contemplate big transgressions." 62 And as such, "clashes" between our internalized idea of social norms and small events (such as taking home a pen from your office) are likely to be washed away by pseudo counter-arguments that our mind comes up with. See more under "Biases."

\section{Identification}

Identification is the conscious, willful following of the witnessed behavior of others. That is, the viewer can subscribe to the witnessed behavior, and thus views it as behavior he/she should (and will) exhibit him/herself. Kelman (1958) describes identification as the state when an individual accepts influence for the reason of establishing or maintaining a "satisfying self-defining relationship to another person or a group." However, the individual believes in the responses adopted through identification, with less regard for the specific content. The behavior is accepted because it is associated with the desired relationship. ${ }^{63}$ This is different from internalization, where the norm is adopted precisely because of the content.

\footnotetext{
${ }^{61}$ Shavell (2010), p. 20, makes a similar distinction in three determinants of compliance behavior: (1) the desire to do social good; (2) the possibility of legal sanctions; and (3) the possibility of social sanctions.

${ }^{62}$ Ariely (2010), p. 279.

${ }^{63}$ Kelman (1958), p. 53.
} 
This matches with what Bicchieri (2009) calls an "empirical expectation": the individual expects a majority of people to follow the specific norm. ${ }^{64}$ Shavell (2010) refers to identification as this phenomenon as "morally tutelary": "that the witnessing of compliance behavior would in some fashion effect a change in the desire of observers to foster the social good and thus to obey [or disobey] the law... In other words, the assumption is that if an observer sees that another individual has sacrificed his or her usual self-interest for the social good - for instance, learns that a colleague has paid income taxes out of a sense of civic duty - the observer may be led to increase the importance (perhaps only temporarily) that he or she attaches to the social good and consequently to obeying the law". ${ }^{65}$

Akerlof (2011) refers to "social categories" to describe how individuals identify with witnessed behavior of others. Those who identify with the witnessed behavior and the underlying norms are dubbed "insiders" and those who cannot identify, "outsiders." "In this model, the decision to adhere to a rule "is part of a worker's identity. Workers feel that they should abide by this restriction; the norm is a goal in and of itself.... Workers would suffer utility losses if others disobeyed the norms, and would retaliate to prevent these losses."67

\section{Conformity}

Conformity relates to the situation in which we accept a norm to not differ from the group, and the perceived risk of detection. Peer pressure and herding are good examples. Both identification and conformity have the same result: certain behavior of others influences the viewer to actively adjust his/her own behavior. Shavell (2010) calls this the "compliance externality": people feeling pressured to act according to certain social norms for fear of social sanctions. ${ }^{68}$ Stout (2011) calls conformity "a fundamental aspect of human nature that shows up consistently in experimental gaming... Experimental games thus demonstrate that, in choosing between selfish and unselfish strategies, people tend to do what they think others will do." ${ }^{69}$ But the difference is that in the case of identification, people purposely want to mirror behavior of others that we (want to) identify ourselves with. Conformity with a norm reflects our fear that others might not consider us part of the group anymore, combined with a (perceived) fear of detection of outlier behavior. The result is the same, the driver is

\footnotetext{
${ }^{64}$ Bicchieri (2009).

65 Shavell (2010), pp. 4, 20.

${ }^{66}$ Akerlof (2011), p. 42.

${ }^{67}$ Ibid., p. 57.

${ }^{68}$ Shavell (2010), p. 4. He also refers to expressions of disapproval, "such as scowling at a person who is seen littering in a park or dissociating oneself from a person who one learns has cheated on his taxes" (p. 22).

${ }^{69}$ Stout (2011), p. 109-10.
} 
different. Bicchieri introduces the phrase "normative expectation [which] is the belief that others expect one to conform to a given norm."70

Summarizing: in addition to social, legal, and market norms per se, behavior of others plays an important role. However, while people mostly are somewhat aware of these effects, there are also influences that are further removed from the conscious individual decision-making processes. These are biases, which are dealt with next.

\section{Biases}

As rules of thumb, heuristic principles, or biases, present easy guides for individual decisionmaking. Heuristic principles give simple overviews in cases where the assessing of probabilities and outcomes would otherwise require more effort. The World Bank refers to heuristic principles as "thinking with mental models": "When people think, they generally do not draw on concepts that they invented themselves. Instead, they use concepts, categories, identities, prototypes, stereotypes, causal narratives, and worldviews drawn from their communities. These are all examples of mental models." ${ }^{71}$ See also Kahneman's "System 1, , referred to earlier. ${ }^{72}$

Biases are based on neurological influences. Genetics and environmental influences during the early human development have profound effects on the brain. The way the brain has developed affects moral choices a person makes, and limits the influence people have on those choices. Some authors, like renowned neurosurgeon Dick Swaab, crudely use this to state: "We accept or reject things, not because we have thought deeply about them, but because we have no choice. Ethics is an outgrowth of our ancient social instincts, designed to do what does not harm the group, as Darwin already pointed out." ${ }^{, 73}$

There are numerous biases; some of the salient ones relevant to the financial sector are listed below:

- Representativeness bias: which rates probabilities based on how elements to be compared resemble each other. Though this kind of stereotypical rating can be useful, it can also be a recipe for disaster "because similarity, or representativeness, is not

\footnotetext{
${ }^{70}$ Bicchieri (2009).

${ }^{71}$ World Bank (2015), p. 11.

${ }^{72}$ Kahneman, D., 2003, "Maps of Bounded Rationality: Psychology for Behavioral Economics," American Economic Review, 93 (5): 1449-75.

${ }^{73}$ Swaab (2010), p. 381-82.
} 
influenced by several factors that should affect judgments of probability."74 Proper application of statistical calculations could counter stereotypical ratings. ${ }^{75}$

- Confirmation bias: highlights how people want to see their own existing beliefs confirmed. Confirmation bias is "an irrational tendency to search for, interpret or remember information in a way that confirms preconceptions or working hypotheses. It is a type of cognitive bias and a systematic error of inductive reasoning."76 Causes can be found in "wishful thinking" (including interpreting the smallest of signs as concluding evidence) and/or strong emotional attachment to certain issues (such as in the areas of religious and political debate).

- Anchoring: relates to overdependence on first-offered information. Described by Tversky and Kahneman, ${ }^{77}$ and subsequently tested in a series of experiments, anchoring, or "focalism," highlights how people will depend too heavily on whatever the first set of data (that is, the "anchor") is that they receive, when making subsequent decisions. Its application can commonly be seen in marketplaces. In bargaining the initial listing price will be used as the anchor by the potential buyer, so that anything lower than the initial listing price will still seem as very reasonable, even though the actual worth of the item is (even) lower. Something similar applies to listed discount prices: the price tag listing an "original" price so the current price will give the potential buyer more of a "bargain feel," as it is anchored to the often much higher "original" price.

- Availability bias: relates to the decision-making based on examples that come to mind immediately. It is grounded in the notion that if something can be recalled, it should be important. ${ }^{78}$ The availability heuristic limits the accuracy of predictions by focusing on events that the individual has experienced him/herself in the past.

- Recency bias: more recent events have stronger impact on our decision-making than older events.

- Salience: shows that real-life experiences create memories about facts that will be recalled more easily than if the same facts were noticed by other means ("seeing is believing").

\footnotetext{
${ }^{74}$ Kahneman (1974), p. 1124.

75 See, for instance, Bayes' theorem (named after Thomas Bayes, 1763), which expresses how a subjective degree of belief should rationally change to account for evidence.

${ }^{76}$ Miller (2009).

${ }^{77}$ Kahneman (1974).

${ }^{78}$ Esgate (2005).
} 
1) "Imaginability": deals with the ability of imagining all the possible outcomes. This, especially in more complex situations, is a difficult task.

2) Action bias: implies that people see any action - even if it would in fact be counterproductive to the goal set out to be achieved - as better than no action whatsoever.

3) Insensitivity to sample size: seeing patterns where they do not exist is more common among gamblers, and possibly investment managers. It relates to the fact that people tend to see patterns in small numbers of results, even though the sampling theory entails that many results will more likely regress to the mean than a small set of results. ${ }^{79}$

There are many other biases, relating, among others, to the aversion of losses, overconfidence in one's own capacities/capabilities, and norms relating to reciprocity and fairness. ${ }^{80}$ Figure 4 provides a comprehensive, grouped overview of biases.

Relying on heuristic principles for decision-making can lead to the illusion of validity. If the outcome predicted by relying on a heuristic principle materializes, it will only serve to boost unwarranted confidence in the bias. ${ }^{81}$ Given the complexity of the financial sector, it is understandable that there is a strong reliance on "experts" and "professionals." Some authors, after the global financial crisis, have been calling for "de-expertising" of experts, as their ascribed level of knowledge grew so large, that there simply was no opposition or even discussion possible. ${ }^{82}$

\footnotetext{
${ }^{79}$ Kahneman (1974), p. 1,125. Another interesting presentation is that of Hersh Shefrin on "BP's failure to debias" in which he describes the need for behavioral corporate finance using the BP oil spill on the Deepwater Horizon as a case example. See, e.g., http://www.prmia.org/recorded-webinar/bps-failure-debias-underscoringimportance-behavioral-corporate-finance.

${ }^{80}$ Masciandaro (2014), p. 5.

${ }^{81}$ Kahneman (1974), p. 1,126.

82 See, e.g., Noreena Hertz's TED talk (https://www.ted.com/talks/noreena hertz how to use experts and when not to?language=en) on democratizing expertise, by means of not just considering opinions of CEOs and specialists, but also staff with practical experience, e.g., in the store, front office, or even on the street. Another example can be found in Dijkstra (2012): "Most decision makers in complex domains... have a lot of experience doing their job, but are often not aware of all relevant factors that should play a role in their decisions. Furthermore, they often cannot fully decompose their judgment or decision; their professional domains are just to[o] complex" (pp.132-33).
} 
Figure 4. Overview of Biases

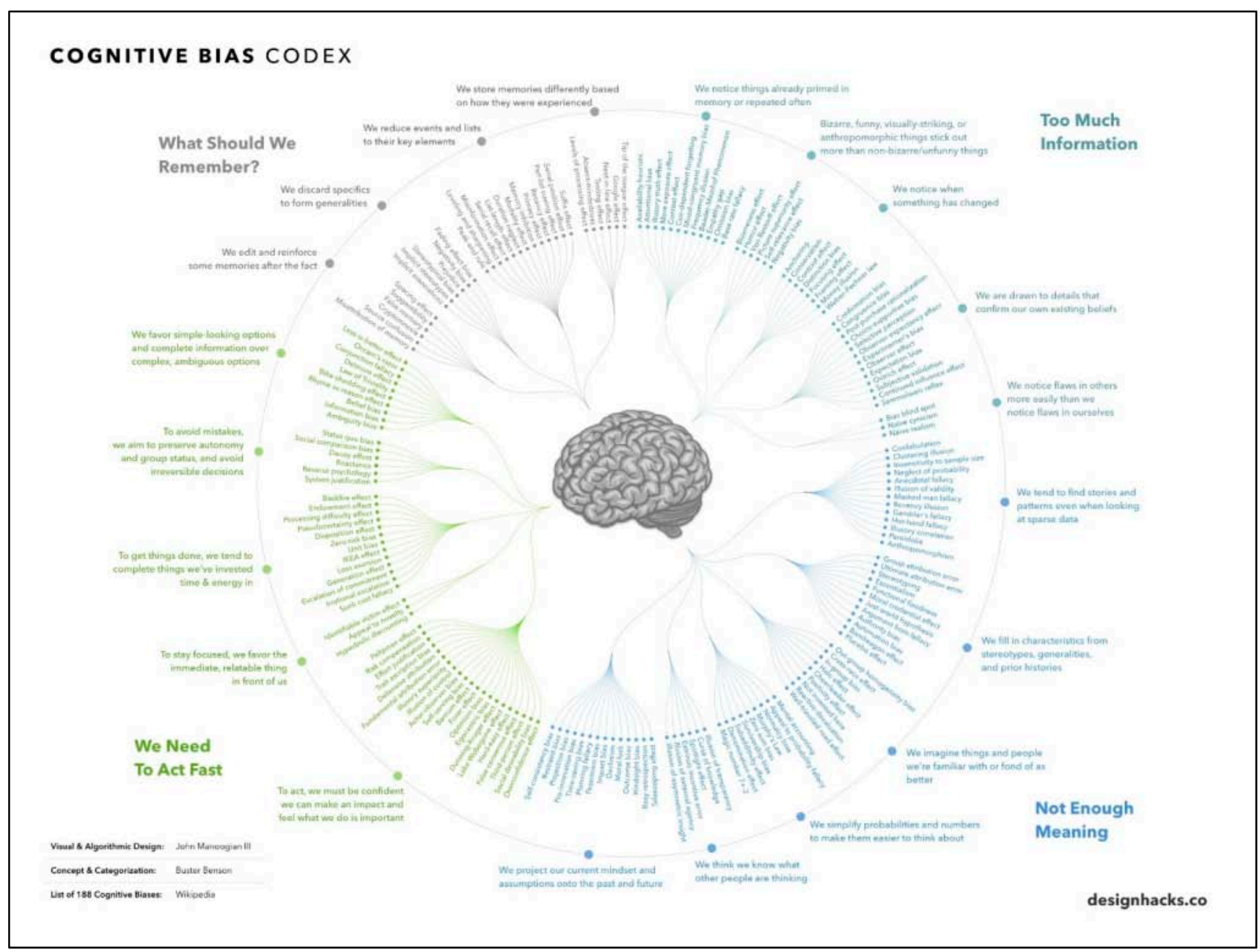

Source: $\underline{w w w . v i s u a l c a p i t a l i s t . c o m ~(J e f f ~ D e s j a r d i n s, ~ S e p t e m b e r ~ 25, ~ 2017) . ~}$

Closely linked to biases are the concepts of bounded ethicality, strong reciprocity, and Prospect theory.

\section{Bounded Ethicality}

Bounded ethicality is based on the term "bounded rationality," which explains how rationality is limited. "Bounded rationality" was first used by Nobel Prize laureate Herbert Simon. Simon explained how even though people act rationally in their decision-making, their rationality is limited by (1) the information they have; (2) their own mental limitations; and (3) the limits on the time frame available for the decision-making. As such, Simon noted, people are more focused on reaching a satisfactory decision, rather than the optimal one.

Bounded ethicality on its turn relates to how people are inclined to act ethically up to a satisfactory rather than an optimal level. The term was introduced by Tenbrunsel and 
Bazerman $^{83}$ to similarly indicate that people are inclined to act ethically, but again the optimal (in this case, the most ethical) decision is often preceded by a satisfactory choice due to human limitations. Ethical decision-making is influenced strongly by biases mentioned earlier.

Bounded ethicality can be demonstrated by two of the three forms of "behavior of others," as described earlier: identification (copying certain behavior because you identify yourself with the person exhibiting that behavior), and conformity (copying certain behavior because of perceived pressure of others). Examples are agreeing with questionable actions at work assigned by your boss, because you want to please your boss; or following other colleagues in your group who do the same thing because you want to feel like part of the group. Tenbrunsel and Bazerman argue that the concept of bounded ethicality demonstrates that people do not make a conscious decision between either the most ethical choice or the most profit-generating choice (if those two extremes can be identified). Rather, people's ethics depend on a range of factors. Experiments have demonstrated that this ambiguity of ethics becomes even stronger when people are faced with choosing between ethical and unethical behavior in situations where a loss is occurring, and even more so when they are dealing with a time-constrained decision period. ${ }^{84}$

Bounded ethicality explains "the ways in which good people do bad things without knowing that they are doing so." 85

\section{Strong Reciprocity}

The concept of "strong reciprocity," introduced by Elenor Ostrom, ${ }^{86}$ outlines how individuals focus on cooperation, even though there might not be a clear benefit to doing so. It is closely related to biases, and challenges the idea that people are motivated only by profit or utility maximization. Instead, it assumes that there are several types of behavior that can emerge under different circumstances, most notably:

- Rational egoists: focusing only on their own gains (and the basis for neoclassical economics' assumptions on utility maximization); and

\footnotetext{
${ }^{83}$ Tenbrunsel (2011).

${ }^{84}$ See, e.g., Kern, M.C., D. Chugh, 2009, “Bounded Ethicality: The Perils of Loss Framing," Psychological Science, Vol. 20, No. 3.

${ }^{85}$ Tenbrunsel (2011).

${ }^{86}$ In Gintis (2005).
} 
- Strong reciprocators: motivated by both material payoffs, as well as by intrinsic preferences (which do not necessarily need to align with material payoffs). ${ }^{87}$

An example of biases within public institutions is the case of the BP Deepwater Horizon oil spill (2010). The US Centre for Progressive Reform concluded that in this case, the regulator did not conduct worst-case analysis, did not consider "reasonably foreseeable significant adverse impacts," and failed to "aggregate low probability risks": ${ }^{8}$ everything that could not be blamed on the risk management systems per se, but on the way risks were not properly assessed in general. In short, the regulator and supervisor gave in to biases, with catastrophic results.

With so many different biases, it might be difficult to differentiate between what is relevant for a specific decision at hand and what is not. Shefrin (2002), when looking at the issues in heavily regulated sectors, focuses on excessive optimism, over-confidence, aversion to a sure loss, and confirmation bias, all of which can be plotted against a concrete number of governance checks and balances in organizations. ${ }^{89}$ The MINDSPACE and EAST frameworks do something similar (see Section II).

\section{Prospect Theory}

Originally developed by Kahneman and Tversky in $1979,{ }^{90}$ prospect theory was presented as a counter-theory to the expected utility theory (that is, that all reasonable people wish to obey the axiom of utility maximization, and most of the time, do so). Prospect theory is based on the assumptions that individuals make decisions on the potential value of gains and losses, rather than the outcome, and biases are used to evaluate such gains and losses. It also highlights that losses outweigh gains (in line with the loss aversion bias, as described earlier).

In summary, there are certain behavioral elements in norms, behavior of others, and biases that we need to understand better. Further exploring the large number of behavioral elements is a necessity for proper understanding of the financial sector and its risks.

\footnotetext{
${ }^{87}$ See, for instance, Ostrom, E., Policies That Crowd out Reciprocity and Collective Action, in Gintis (2005), p. 253.

${ }^{88}$ Center for Progressive Reform (2010), pp. 3-4.

${ }^{89}$ Shefrin (2002), pp. 13-42. In relation to financial risk management he divides the biases into three themes: (1) heuristic-driven themes (e.g., gambler's fallacy, overconfidence, availability bias); (2) frame dependence (e.g., loss aversion, mental accounting, risk tolerance); and (3) inefficient markets (e.g., representativeness, loss aversion, overconfidence).

${ }^{90}$ D. Kahneman, A. Tversky, 1979, Prospect Theory: An Analysis of Decision under Risk, Econometrica, 47(2), pp. 263-91.
} 
Section II builds on this by applying the insights of Section I to financial supervision, regulation, and central banking.

\section{Practical Take-Out for Financial Supervisors, Regulators, ANd Central BANKS}

Nout Wellink, former chair of the Basel Committee of Banking Supervisors (BCBS) and former president of the Dutch Central Bank:

Recently I was at a gathering of hedge fund managers in London, people from the "dangerous" areas of the financial system. As I talked about the proposals of Basel III ... one of the attendees responded, "In about six months, I will have already invented something else." I told him, "Do you have about six months? Within one day I can come up with something new, it is not that difficult." I then told him we know that human reason always tries to escape rules. But if a banker actively searches the boundaries of the law, he is not trustworthy. For he knows that regulations have a purpose. He must, if there are good grounds for such regulation, not consciously try to escape those rules.... I think there must be a candid conversation with people in the financial sector to make them aware of the limits of a legalistic view. ${ }^{91}$

This paper started with signaling that in financial regulation and supervision, behavioral elements play a limited role. More comprehensive financial regulation and supervision could consider the different norm contexts, how individual behavior is shaped by behavior of others, and behavioral biases. This could allow regulation and supervision to more comprehensively address individual decision-making and its risks to the financial sector.

The following subsections explore practical approaches by central banks and financial supervisors. They examine two country experiences in particular: (1) the Netherlands and its central bank —De Nederlandsche Bank (DNB) — as one of the first financial regulators and supervisors to start combining behavioral elements from the social norm context in its regulation, and day-to-day supervision; and (2) the UK and its Behavioral Insights Team (BIT), as one of the first policy teams to focus specifically on behavioral insights. These two examples provide a helpful sense of direction for financial policymakers. The paper then looks at additional behavioral possibilities to enhance supervision and regulation.

\section{A. Framework for Integration of Behavioral Elements into Financial Supervision and Regulation}

There are three main areas into which financial supervisors and regulators should incorporate behavioral knowledge and expertise (Figure 5):

\footnotetext{
${ }^{91}$ Jansen (2011), p. 133.
} 
1) Research: conducting academic research into behavioral economics and finance;

2) Supervision: practicing behavioral supervision in addition to regular supervision; and

3) Policy/regulation: applying behavioral knowledge to financial regulation and policy development.

\section{Figure 5. Framework for Integration of Behavioral Elements into Financial Supervision and Regulation}

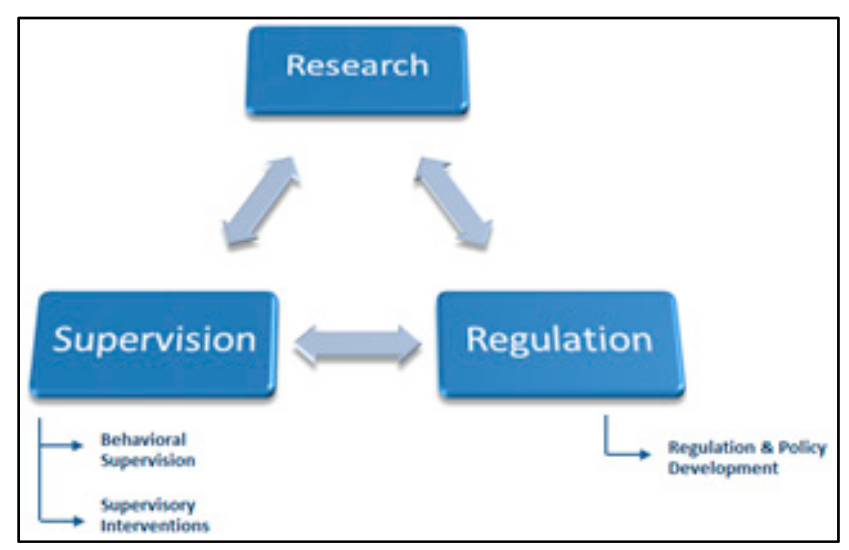

Source: Author.

\section{Research-General}

Research forms the basis for understanding theoretical behavioral concepts, before being able to implement them in practice. Central banks and supervisors and/or regulators should create an environment conducive to conducting research into behavioral aspects of the financial sector. Research possibilities offer ways to transcend the operational level of supervision and regulation.

This ideally would extend beyond the realm of supervised entities into the decision-making of the central bank/supervisor itself as well, as the Bank of England's (BoE) chief economist succinctly pointed out in his 2014 speech titled, "Central Bank Psychology": "Behavioral biases afflict us all, in every activity from setting concrete to setting interest rates, from stress-testing steel to stress-testing banks. Central banks cannot be immune. Because central banks' judgments affect society at large and in large ways, it is important there are institutional means of safeguarding against these biases." 92

\footnotetext{
${ }^{92}$ Haldane (2014). Haldane highlights four biases that especially "may pose a particular [central bank] policymaking challenge, i.e., (1) preference bias, (2) myopia bias, (3) hubris, and (4) groupthink. (See subsection D, Role of Central Banks.)
} 


\section{Research-Monetary Policy}

Monetary policy decision-making is the topic of behavioral research as well. For instance, Lombardelli, Proudman, and Talbot (2002) conducted experiments on monetary policy decision-making under uncertainty, finding that groups (for example, a monetary policy committee) make better decisions than individuals. Information-sharing and observing other committee members' choices add to the quality of decision-making.

Similarly, Brazier, Harrison, King, and Yates (2006) developed an inflation forecasting model based on the use of heuristics. They find that such a model, incorporating specific heuristics (that is, lagged inflation and announced inflation targets), stabilizes the economy better than do monetary policy rules.

Additional research examples can be found on regulatory capture (Veltrop and De Haan, 2014) and inattention in financial markets (Ehrmann and Jansen, 2012). The BoE's “One Bank Research Agenda" (2015) highlights a number of potential areas for further research, varying from biases that may arise in judgment-based supervision" 93 to "it may be fruitful to collect firsthand data from surveys or experiments to improve understanding of market participants' choices and demands." 94

\section{Supervision: Case Example of De Nederlandsche Bank}

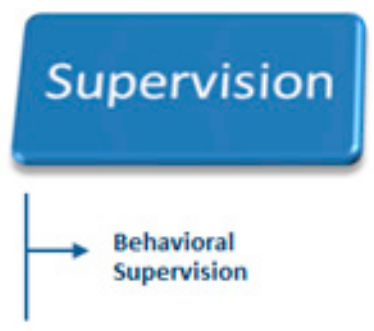

As a prerequisite for behavioral supervision, supervisors (most notably top executives and senior management) must understand the need to incorporate behavioral elements into the field of financial supervision. Subsequently, hiring knowledgeable staff and developing staff expertise are imperative. This goes for central banks, ${ }^{95}$ supervisors, and regulators.

The central bank of the Netherlands (De Nederlandsche Bank [DNB]) offers one of the first examples of how behavioral supervision could be shaped. In 2009, DNB published a policy

\footnotetext{
${ }^{93}$ Bank of England (2015), p. 22.

${ }^{94}$ Bank of England (2015), p. 25.

${ }^{95}$ See, for instance, Favaretto, F., and D. Masciandaro, 2016, Too Little, Too Late? Monetary Policymaking Inertia and Psychology: A Behavioral Model; and, Masciandaro, D., P. Profeta, and D. Romelli, 2016, Gender and Monetary Policymaking: Trends, Drivers and Effects.
} 
paper titled, "The Seven Elements of an Ethical Culture." "96 It describes a set of behavioral ways that should be used in addition to the more standardized controls (mostly capital and liquidity measures and corporate governance related mechanisms). Figure 6 shows the elements DNB regards as key "cultural elements" and their positioning:

\section{Figure 6. DNB's House of Cultural Elements}

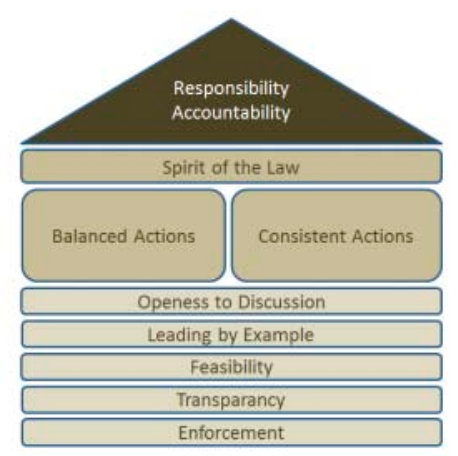

Source: De Nederlandsche Bank (2009).

In its day-to-day supervision, an expert team that includes psychologists and sociologists ${ }^{97}$ aids DNB's regular supervisors with behavioral expertise. This includes, for instance, conducting behavioral surveys within supervised entities, participating in company board meetings as observers, conducting behavioral interviews with board members, and generally creating further awareness among supervisors and supervised entities alike that behavior and culture are crucial elements of effective supervision — and of companies effectively managing risks.

DNB's behavioral Expertise Center also has the mandate to conduct its own thematic examinations. These examinations cover one specific behavioral theme (for instance, leadership or decision-making), and numerous supervised entities (banks, insurance companies, pension funds) are subject to further examination through the course of roughly one year. This is done in close cooperation with DNB's regular supervisors. However, it is the Expertise Center that chooses the behavioral theme, the situation to be examined (for instance, decision-making surrounding a takeover), and draws up final conclusions with suggestions for interventions to be made. It does not conduct interventions (such as the issuance of warnings) on its own; this remains the responsibility of the supervisory team.

Early recognition of behavioral risks is an important aspect of this more extensive risk management approach. Examining and assessing behavior that might give an early warning

\footnotetext{
$96 \mathrm{http}: / /$ www.dnb.nl/en/binaries/The\%20Seven\%20Elements\%20of\%20an\%20Ethical\%20Culture_tcm47233197.pdf.

${ }^{97}$ DNB's Expertise Center on Governance, Conduct, and Culture.
} 
of prudential risks is key. This will lead to a different prioritization. Having an overly dominant CEO can, for example, lead to poor investment decisions. As such, the focus on behavior leads to identifying root cause issues in a company's governance, and is a cornerstone of prudential risk management. In some banks, this could lead to a capital add-on under Basel's Pillar 2.

DNB published an overview report on behavior (conduct) and culture supervision in April 2013, dubbed "Leading by Example - Conduct in the Board Rooms of Financial Institutions." The report consists of findings of thematic examinations of about 30 financial institutions in the Netherlands. It describes the goal of behavioral supervision as being able to "pinpoint problems at an early stage, before they result in poor [financial] performance."

Based on these findings, the report lists four key areas that DNB expects financial institutions to address:

1) Specific action to enhance attention to behavior and group dynamics (for instance: "Patterns of group dynamics were regularly and openly discussed both in day-to-day operational meetings and during regular off-site sessions");

2) Sound judgment ("This means that their members must actively ask questions, engage in constructive discussion and challenge one another in the context of forming a judgment");

3) Organizing critical dialogue ("This helps ensure adequate discussion of all relevant risks and prevents decision-making from becoming overly dependent on interpersonal dynamics"); and

4) Flexible leadership style for chairpersons ("Chairpersons should be capable of flexibly applying several leadership styles, depending on the situation"). ${ }^{98}$

It goes on to list a number of best practices, including examples of company boards organizing coaching and strategy sessions, as well as the deliberate breaking down of complex decision-making processes into smaller, less complex ones.

Last, DNB's behavioral supervision also consists of efforts trying to influence the culture of the financial sector at large - and its key players, such as board members and senior managers. Throughout the year, several events are organized (called "rationale for change"), such as round table meetings, seminars with speakers from the Netherlands or abroad, and discussion settings surrounding the publication of the outcomes of DNB's thematic examinations, as described earlier. These events are always hosted by the executive management of DNB. Participants are key players from the financial sector. The meetings serve as a platform to discuss, promote, and generally underline the need for attention for behavioral aspects in the financial sector.

${ }^{98}$ Leading by Example, p. 2. 


\section{Regulation \& Behavioral Policy Development}

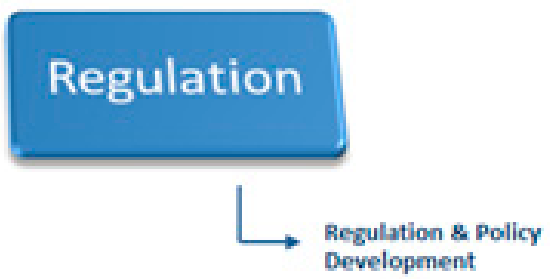

There is also a need to look at behavioral aspects from a regulatory and policy development view. The long-term question is how to draft regulations that incorporate behavioral aspects from the start. The WDR 2015 is one of the first comprehensive reports at the international level outlining this need to start with policy development: "paying attention to how humans think ... can improve the design and implementation of development policies and interventions that target human choice and action (behavior). To put it differently, development policy is due for its own redesign based on careful consideration of human factors." $" 99$ Earlier, in 2013, the European Commission had contracted a report outlining that policymaking throughout its Directorates-General could benefit from "a better understanding of people's behavior."100

Understanding people's behavior is relevant, for instance, for anti-corruption regulations. Feldman (2017) points out that rules on conflicts of interest and corruption could be drafted in such a manner that they in fact lower the barriers to misconduct. For instance, the so-called four eyes principle, generally considered an appropriate check and balance, might be less effective when considering that "when people work together in dyads, they are more likely to engage in wrongdoing relative to how they would have behaved individually," as some research shows. ${ }^{101}$

\footnotetext{
${ }^{99}$ WDR (2015), p. 2.

${ }^{100}$ European Commission (2013), p. 3.

${ }^{101}$ Feldman (2017), referring to Weisel, O., S. Shalvi, 2015, "The Collaborative Roots of Corruption," Proceedings of the National Academy of Sciences, 112 (34), pp. 10651-56.
} 
Remuneration policy is another area where behavioral aspects are highly relevant. Current regulations on curbing and capping bonuses and other forms of monetary rewards do not consider that "nonmonetary rewards are harder to resist, especially by good people ... Regulators need to worry about nonmonetary rewards at least as much as they do about monetary ones." Relevant here is that certain studies analyzed situations lacking monetary reward issues, but rather with "ties of shared identity or ideological perspective between regulators and those being regulated." 102

Therefore, supervisors and regulators might need to make people feel supported in their intrinsic motivations. As discussed in Section I, regarding "strong reciprocity," Ostrom ${ }^{103}$ highlights that public institutions should ensure that individuals focused on solving collective action problems are not only enabled to do so, but also protected from "free-riders and untrustworthy partners." This would otherwise allow crowding out of intrinsic motivations, especially when those institutions make individuals feel that "their own self-determination or self-esteem is adversely affected." 104 She refers to Frey and Jegen $(2001,594-95)$ and their identification of psychological conditions that are likely to lead to either crowding in or crowding out:

102 Feldman (2017), referring to the following studies:

- $\quad$ Lessig, L., 2011, Republic, lost (New York: Grand Central).

- Dana, J., G. Loewenstein, 2003, “A Social Science Perspective on Gifts to Physicians from Industry,” Jama, 290 (2), pp. 252-55.

- Veltrop, D., J. De Haan, 2014, “I Just Cannot Get You Out of My Head: Regulatory Capture of Financial Sector Supervisors,” DNB Working Paper, 410, January.

- Jones, D., 2000, “Group Nepotism and Human Kinship,” Current Anthropology, 41 (5), pp. 779-809.

- Kwak, J., 2013, “Cultural Capture and the Financial Crisis,” Preventing Regulatory Capture: Special Interest Influence and How to Limit It, pp. 71-98.

103 In Gintis (2005).

${ }^{104}$ In Gintis (2005), pp. 259-60. 
1) External interventions crowd out intrinsic motivation if the individuals affected perceive them to be controlling. In this case, both self-determination and self-esteem suffer, and the individuals react by reducing their intrinsic motivation in the activity controlled.

2) External interventions crowd in intrinsic motivation if the individuals concerned perceive it as supportive. In this case, self-esteem is fostered, and individuals feel that they are given more freedom to act, thus enlarging self-determination."

Corporate governance is an area where behavioral policy development and regulation can be integrated with relative ease. Behavioral elements in current financial regulation and supervision are mostly linked to issues of corporate governance, given the link to organization and incentives. As the Group of Thirty concluded: "Values and culture may be the keystone of financial institutions' governance because they drive behaviors of people throughout the organization and the ultimate effectiveness of its governance arrangements." 105 (Box 2 provides an overview of corporate governance.) Regulations on corporate governance often relate to more qualitative aspects. This includes standards relating to remuneration policies, suitability/fit and proper, structuring of (senior) management, nonfinancial risk management, internal audit, and internal supervision and independence requirements.

The effects of the work environment on individuals are important for supervisors to note. The different roles that corporate employees are given define which norm that individual applies. An ethics officer will most likely be more inclined to appeal to the social norm context than a trader. In addition, most profit-driven companies can act in ways that individual employees would not agree to from a social norm perspective, because of the strong separation and division of specific roles and responsibilities. ${ }^{106}$ Distance in space and time between individuals in a company and the people their decisions might affect also could lead to social norms being less prevalent in favor of legal and/or market norms. ${ }^{107}$

Practically, supervisors and regulators should incorporate behavioral aspects into their approach of governance. They could do so in two ways:

1. Making behavioral aspects of governance rules visible, ex ante. This involves taking (a) norms; (b) behavior of others; and (c) biases into account when drafting or adjusting governance rules. Application of a behavioral policy framework (see, for instance, the UK's example in the next subsection) is one concrete option.

2. The next step concerns the applicability of this new kind of rule, ex post. This is a matter of how to influence financial institutions as effectively as possible, in other words, how to

\footnotetext{
${ }^{105}$ Toward Effective Governance of Financial Institutions, G30, April 2012, p. 15.

106 Sparrow (2000), p. 63; Lawrence (2002).

107 See, e.g., Braithwaite (1995), p. 4, on why "decent people do indecent deeds."
} 
convey these standards in a manner that contributes most to achieving the desired (compliance) result.

The governance rule itself would need to be made more robust, by means of making behavioral aspects visible. Contemporary references include the European Central Bank's (Single Supervisory Mechanism) Guide to Banking Supervision, ${ }^{108}$ the European Banking Authority's Guidelines on Internal Governance, ${ }^{109}$ and the European Capital Requirements Directive $I V .^{110}$

Finally, policymakers and regulators self-awareness of their own behavioral biases is needed as well. If knowledge of human behavior is to be used in drafting rules, reflection on policymakers' own biases is helpful: "Being aware of these potential pitfalls can help when developing and pushing forward new policies." 111 Some economists have pointed out that quantitative forecasting needs to be corrected for optimism bias of policymakers, such as those at the IMF and the World Bank, as "economists systematically make optimistic forecasts, giving more weight to recent growth performance than is justifiable by historical experience." 112

\section{Incorporating Behavior into Rules: Case Example of the UK}

The UK's British Behavioral Insights Team (BIT) has been leading the way in incorporating behavior into rules, and developed a methodology called MINDSPACE. ${ }^{113}$ This consists of a list of behavioral elements created for policymakers in the UK. It offers an academically based framework with nine crucial factors that influence human behavior-based on much of the research described in Section I of this paper. The name is taken from a report published in 2010 by the British Institute for Government (IfG). The report originated from the British Cabinet Office, which was keen to explore how scientific insights into human behavior might

\footnotetext{
${ }^{108}$ ECB (2014), para. 72, p. 35.

${ }^{109}$ EBA (2011), para. 20, p. 32.

${ }^{110}$ EU (2013), see most notably article 98, sub 7, outlining the need for supervisors to examine "corporate culture and values" in the so-called Supervisory Review and Evaluation Process (SREP).

${ }^{111}$ European Commission (2013), p. 6. Interestingly, this report (footnote 7) indicates that the European Commission established a summer school in behavioral economics for EU policymakers in 2012 to create more awareness of their own biases.

112 Ho and Mauro (2015), p. 42.

${ }^{113}$ MINDSPACE: influencing behavior through public policy. 2010. Available at: http:/www.instituteforgovernment.org.uk/sites/default/files/publications/MINDSPACE.pdf. A more simplified version, dubbed "EAST: Easy, Attractive, Social, Timely," has subsequently been published by the BIT in order to make the concepts underlying MINDSPACE more pragmatic for policymakers. See also: http://wwwbehaviouralinsights.co.uk/publications/east-four-simple-ways-to-apply-behavioural-insights/.
} 
offer help to policymakers. The IfG report points out that there are many interesting ideas within behavioral sciences, such as social psychology and behavioral economics. The drawback is that it is very difficult for policymakers to make a distinction between central aspects and side issues. By way of solution, the report selects nine important aspects of behavior, thereby providing a guideline for policymakers as well as setting limits.

Following the BIT example, other behavioral units have been set up elsewhere in the world. A notable example was that of the so-called "White House Social and Behavioral Sciences Team," led by Maya Shankar, under the Obama administration. Shankar indicated that "our hope is that in addition to demonstrating the impact of behavioral science in policy, we'll also be able to improve the quality of evaluation that goes on in the federal government and to develop ongoing knowledge and an ongoing knowledge base of what works and what doesn't."114 Other examples are that of the Australian Behavioral Insights Unit, set up under the New South Wales Government, ${ }^{115}$ and Singapore's Ministry of Manpower-both initiatives set up in cooperation with the UK BIT.

Table 1 describes the MINDSPACE behavioral aspects (columns 2 and 3), and gives examples (column 4). The examples in the table are drawn from different policy domains (health care, hospitality industry, and advertising). The examples show that the behavioral aspects that confront policy, legislation and regulations, standardization, and supervision are by no means limited to the financial sector. MINDSPACE combines knowledge of social and market norms, behavior of others (internalization, identification, as well as conformity), and behavioral biases, as described in Section I.

\footnotetext{
${ }^{114}$ Nesterak (2014); see also "Using Behavioral Science Insights to Make Government More Effective, Simpler, and More People-Friendly," www.whitehouse.gov, February 9, 2015.

115 See New South Wales Department of Premier and Cabinet. http://bi.dpc.nsw.gov.au/, October 19, 2014.
} 


\section{Table 1. MINDSPACE: Behavioral Elements and Examples}

\begin{tabular}{|c|c|c|c|}
\hline & Aspect & Explanation & Examples \\
\hline 1 & Messenger & $\begin{array}{l}\text { The messenger determines our reaction to } \\
\text { information. }\end{array}$ & $\begin{array}{l}\text { People do not always want to listen to } \\
\text { messages from a belittling government. } \\
\text { Putting up "experts" might have more } \\
\text { influence. }\end{array}$ \\
\hline 2 & Incentives & $\begin{array}{l}\text { People do not always react purely rationally to } \\
\text { stimuli. }\end{array}$ & $\begin{array}{l}\text { Losing a sum of money has a bigger impact } \\
\text { than winning the same amount; bonuses } \\
\text { prompt us to take bigger risks than we } \\
\text { should. }\end{array}$ \\
\hline 3 & Norms & $\begin{array}{l}\text { We conform to the behavior of those around us; } \\
\text { we want to meet expectations and follow } \\
\text { examples. }\end{array}$ & $\begin{array}{l}\text { Being silent in a library or on the train; } \\
\text { providing information on the average energy } \\
\text { consumption of neighbors causes us to } \\
\text { reduce our own energy consumption. }\end{array}$ \\
\hline 4 & Defaults & $\begin{array}{l}\text { We consciously or subconsciously choose the } \\
\text { standard option and do not make an active } \\
\text { choice. }\end{array}$ & $\begin{array}{l}\text { Organ donation is not the default position in } \\
\text { many countries, so there are fewer people on } \\
\text { the donors register; notices in hotel rooms } \\
\text { with the standard option "reuse the towels" } \\
\text { lead to more reuse. }\end{array}$ \\
\hline 5 & Salience & $\begin{array}{l}\text { New, simple, accessible, and rapid information } \\
\text { attracts our attention. That information also sticks } \\
\text { better; "anchor point." }\end{array}$ & $\begin{array}{l}\text { We quickly scan newspaper headlines. When } \\
\text { confronted with too much information, we do } \\
\text { not make a choice. }\end{array}$ \\
\hline 6 & Priming & $\begin{array}{l}\text { Our actions are driven by hints (words, images, } \\
\text { smells, etc.) that we consciously or } \\
\text { subconsciously observe. }\end{array}$ & $\begin{array}{l}\text { A picture of a smiling face causes us to take } \\
\text { bigger helpings in cafeterias. }\end{array}$ \\
\hline 7 & Affect & Emotion, mood, and feeling determine behavior. & $\begin{array}{l}\text { Results of sporting contests influence share } \\
\text { prices. }\end{array}$ \\
\hline 8 & Commitments & $\begin{array}{l}\text { We try to keep promises and act reciprocally to } \\
\text { prevent reputational damage. }\end{array}$ & Losing weight together is more effective. \\
\hline 9 & Ego & $\begin{array}{l}\text { We want to feel good about our actions. We filter } \\
\text { and label. Positive self-image. }\end{array}$ & $\begin{array}{l}\text { Attributing success to ourselves, mistakes to } \\
\text { others. }\end{array}$ \\
\hline
\end{tabular}

Sources: MINDSPACE, explanation and examples by author.

The take-out for regulators and supervisors is the need to draft internal guidance on how to incorporate behavioral aspects into their day-to-day policy work. This guidance would offer policymakers a framework for when they are drafting rules within, for instance, their working groups under the BCBS, the ECB's Single Supervisory Mechanism, the European Banking Authority (EBA), the European Insurance and Occupational Pension Fund Authority, the Financial Action Task Force, and so on. Regulatory/supervisory guidance should translate MINDSPACE to a practical handset to at least make staff aware of the hidden choices they are making while drafting rules and regulations, and the effect this might have on supervised entities.

Such an approach would be successful in an environment dubbed "responsive regulation" by Ayres and Braithwaite. "Responsiveness" would generate different policy ideas that go beyond regulatory and deregulatory solutions. The regulator does not look for optimal solutions. Instead, the regulator examines solutions that simply respond better than others to "the plural configurations of support and opposition that exist at any particular moment in 
history." 116 Sparrow refers to Howard, who observed: "Law can't think, and so law must be entrusted to humans, and they must take responsibility for their interpretation of it."117 Sparrow adds: "Part of the solution to the overwhelming mass of centralized, prescriptive regulations ... is to give regulators greater latitude and discretion, so they can make sensible judgments in response to individual situations - because the application of blanket prescriptions leads, in particular cases, to foolishness." 118 However, this also creates a supervisory dilemma: more discretion for the supervisor generates more responsibility.

Applying behavioral knowledge into policy- and rule-making also comes with a responsibility for policymakers to use that knowledge carefully. Using behavioral elements in policy, popularly called "nudging" (after the book Nudge (2008), by Sunstein and Thaler ${ }^{119}$ ) implies that the subjects of that policy are by nature not always aware of the way they are being guided/nudged into making certain decisions.

A recent study by Sunstein ${ }^{120}$ among Americans (distinguishing between political factions of Republicans, Democrats, and Independents) found clear likes and dislikes for applying certain nudges. Those who created dislike were mostly linked to default rules (such as assuming for census purposes that people would be Christian, men taking the last name of their wives upon marriage, or tax payers contributing an amount to the Red Cross - all unless stated differently) and certain education and information-based nudges. Generally favored nudges related to health and safety issues (such as salt content or genetically modified organisms). Sunstein concluded that people reject nudges that (1) would be based on illicit motivations (favoring a specific religion or political party); (2) are inconsistent with the interests or values of the majority: "if a default rule harms a majority, it is unlikely to have much appeal": and most likely (3) that are seen as clearly manipulative. If behavioral policymakers apply nudges, it would at least require careful examination, transparency to society, and probably tackling some "serious ethical questions.", 21

\section{Effective Behavioral Influence: Application of the Rule}

A second, equally important area where fleshing out of behavioral aspects is needed relates to the (ex post) application of the rule (as opposed to development of the rule, as discussed in the previous paragraphs). This relates to how regulators and supervisors could influence the

\footnotetext{
116 Sparrow, p. 38.

${ }^{117}$ Howard, P., 1994, The Death of Common Sense: How Law is Suffocating America, Random House (New York).

118 Sparrow, p. 4.

119 Thaler's work on behavioral economics was recognized by the 2017 Nobel Committee, when it awarded the Nobel Prize for Economics to him.

${ }^{120}$ Sunstein (2015).

${ }^{121}$ Sunstein (2014).
} 
behavior of people and institutions as effectively as possible. Legislation and regulations, including at the supervisory level, generally take a limited number of forms. The rules incorporated in those instruments will increasingly take human behavior into account, as argued earlier. But the application itself of those rules also requires that legislators and regulators consider how people react to them.

An example is that of a central bank/financial supervisor issuing a rule on how commercial banks need to report data to the central bank. The supervisor will need to ask whether the legal form of the rule is the most appropriate method of influence. There are also questions to be asked about the method of communication. The goal is effective behavioral influence. Among other things, this will involve making a conscious choice for an influencing strategy: normative (persuading and/or directing), educational (supporting and/or inspiring), or coercive (punishing and/or rewarding). Here, too, MINDSPACE (see Table 1) can help. For example, the Messenger element can guide supervisors to explore who is the best party to convey a message to the market, or specific financial institutions: should it be the supervisor, the central bank, the ministry of finance? Should the message be delivered via a directive, a regulation, a formal letter, or for instance via a seminar, or workshop?

Another practical example based on corporate experiences is Shefrin's model of culture and governance. Shefrin developed a qualitative model plotting key governance elements together with key biases to assess an entity's risk management. He based this model on examples of risk management and governance failures, and how underlying biases allowed these to happen (the case of BP's oil spill on the Deepwater Horizon platform in 2010 among them). The more the specific biases appear in the governance aspects, the more likely it is that risk is not managed (and mitigated) properly (Table 2).

Table 2. Shefrin's Model for Culture and Governance

\begin{tabular}{|l|c|c|c|c|}
\hline \multicolumn{1}{|c|}{ Culture } & Excessive Optimism & Overconfidence & Sure Loss Aversion & Confirmation Bias \\
\hline Standards & $?$ & $?$ & $?$ & $?$ \\
\hline Planning & $?$ & $?$ & $?$ & $?$ \\
\hline Incentives & $?$ & $?$ & $?$ & $?$ \\
\hline Information Sharing & $?$ & $?$ & $?$ & $?$ \\
\hline
\end{tabular}

Source: Course on Behavioral Finance, Hersh Shefrin, Amsterdam Institute of Finance, 2011.

\section{Behavioral Insights Team}

A Behavioral Insights Team (BIT) could be helpful in application and enforcement of the rule, in addition to having a role in drafting the rule. A BIT would be a minimum requirement to integrate both policy and supervisory interventions into actual practices. Such a team could consist of a small group of behavioral experts, working in different departments (Communication, HR, and Supervisory Policy). Its main goal would be to contribute to the effectiveness of several projects by broadening the horizon with insights from behavioral 
theory. That is, instead of taking the regular procedure in a supervisory intervention or developing a new policy, the behavioral experts would highlight the actual behavior that is to be influenced. What would the possible hindrances in behavioral routines, emotional attachments, or social patterns be that could lower the effectiveness of the supervisory action? And how could a solution to the problem be found, by making use of frameworks such as "MINDSPACE” (see also Table 1)?

\section{International Context}

Both on the European level and on a global level, the behavioral policy development approach has gathered support. The Institute of International Finance (IIF) hosted a highlevel seminar in June 2013 with several board members of global financial institutions and financial supervisors, as well as representatives of the Financial Stability Board (FSB). The IIF summarized the seminar as follows: "There are ... some areas where useful work can already be done (and is being done) ... Whether there are insights from behavioral economics that can be useful and if so how to translate them into improvements. Supervisors... are doing pioneering work in this field, looking for instance at cases where firms might appear to be doing well, but there might be patterns of behavior that could create risk and how supervisors should react." 122

At the European level, the Capital Requirements Directive ${ }^{123}$ brings "corporate culture" into the supervisory domain: "The review and evaluation performed by competent authorities shall include governance arrangements of institutions, their corporate culture and values, and the ability of members of the management body to perform their duties." The EBA uses similar words in its Guidelines on Internal Governance. ${ }^{124}$ In the context of the new European banking union (that is, financial supervision conducted by the ECB), diligent efforts are being made to shape behavioral aspects as part of the new European supervisory manual.

Summarizing: behavioral elements can play a crucial role in:

- Drafting of new rules (what is the goal of the rule supposed to be); and

- Application of the new rules (how to ensure that the format of the rule achieves this goal).

Additionally, behavioral elements could be applied in a third, subsequent area:

\footnotetext{
122 IIF, pp. 5-6.

${ }^{123}$ CRD IV, articles 86, 87, and 94.

${ }^{124}$ EBA GL 44: para. B3m, 10.2 (“professional and responsible behavior”).
} 
- Enforcement of the new rules (how to monitor, and where necessary enforce, compliance with the rules). This is discussed in the following paragraphs.

\section{B. An Even Further Enhanced Supervision Mechanism}

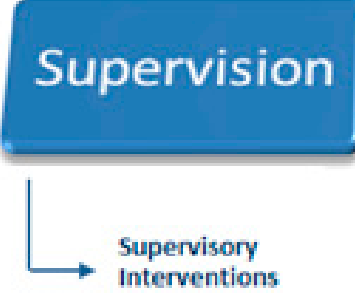

Behavioral aspects could also be included in a toolkit of supervisory interventions: (in)formal interventions applied to supervised entities.

Over the past years many examples of formal penalties, fines, and revoked licenses have emerged. Examples include the US Justice Department's (DOJ) fine of \$780 million for UBS hiding accounts of American customers (2009); ${ }^{125}$ the US Commodity Futures and Trading Commission penalty of $\$ 325$ million for RBS in the Libor case, with an additional $\$ 150$ million fine from the DOJ; ${ }^{126}$ and a US Security and Exchange Commission (SEC) fine of $\$ 500$ million for ABN AMRO Bank / RBS due to violations of the International Emergency Economic Powers Act Trading with the Enemy Act as well as a violation of the Bank Secrecy Act. ${ }^{127}$

Regulators and supervisors have numerous ways to enforce compliance by supervised entities or individuals. The SEC, for instance, can file for application of civil sanctions (such as barring or suspending a corporate director or officer), and can apply administrative sanctions (for instance, cease and desist orders, suspension of registrations, monetary penalties). ${ }^{128}$ These could all be referred to as formal interventions, as opposed to semiformal, or more informal interventions such as presenting supervision findings, sending letters or discussing issues at hand with relevant staff of the supervised entity. These sanctions also differ in intensity, something that Sparrow (2000) calls "graduated

\footnotetext{
${ }^{125} \mathrm{http}$ //ubslosseslawsuits.com/ubs-in-the-news/4-ubs-pays-\$780-million-fine-and-agrees-to-reveal-customeridentities.html.

${ }^{126} \mathrm{http}$ ://www.telegraph.co.uk/finance/newsbysector/banksandfinance/9853088/RBS-Libor-fine-what-theauthorities-said.html.

127 http://www.justice.gov/opa/pr/2010/May/10-crm-548.html.

${ }^{128} \mathrm{http} / /$ www.sec.gov/news/newsroom/howinvestigationswork.html.
} 
sanctions." 129 The softer interventions are listed at the bottom and are more frequently applied. The tougher interventions are listed higher in the pyramid; their use declines as you reach the top of the pyramid. ${ }^{130}$

A general supervisory enforcement approach has several categories, with specific instruments that can be used (Figure 7). The categories can partly overlap. Preventive measures, such as consultations or investigations, match with more day-to-day supervision. Protective measures are generally of a more intensive (or even invasive) nature, whereas punitive measures are focused on, preventing contagion risk and setting an example of nontolerated actions. Intrusive supervisory interventions, related to resolution and nationalization, for example, are supposed to be used in extreme cases only, and rank between protective measures (of depositors and shareholders) and punitive measures (when, for instance, looking at the personal liability of directors and senior staff).

\section{Figure 7. Categories and Examples of Supervisory Interventions}

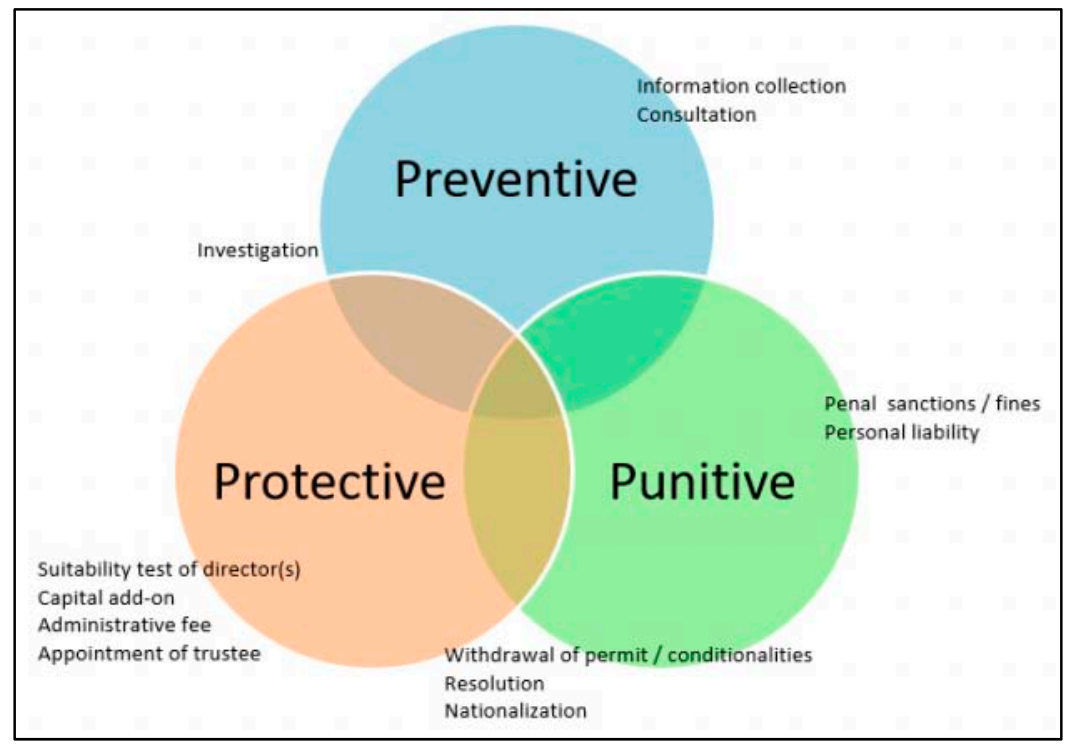

Source: Author.

In the standard toolkit of supervisory interventions, behavioral elements are most often not intentionally included. Yet preventive interventions are well suited for applying behavioral knowledge. This level includes interventions such as drawing up a formal letter to an institution, requesting board members to come for a consultation to the central

\footnotetext{
${ }^{129}$ Sparrow (2000), p. 39.

130 One way of moving through the hierarchy of interventions is that of the US FDIC Prompt Corrective Action mechanism. This mechanism gradually increases the amount of capital that an FDIC-supervised entity needs to hold.
} 
bank/supervisor, starting an investigation, and requesting the institution to submit relevant documents (transcripts of board meetings, accounts, and so on). The text of a formal letter, the way board members are approached, the way documents are requested are all relevant for how one or more persons at the supervised entity would react. A formal letter could give a feeling of distrust and of warning. But it is not clear if this would lead to acceptance of the norm that is being set or to mere factual compliance (leaving space for "creative compliance," as mentioned in Section I), ${ }^{131}$ or even to outrage on the part of the supervised entity, and thus perhaps to defiance of the norm.

\section{Systemic Risk Assessment}

Another supervision area where behavioral aspects could usefully be included is in assessing systemic risk. Systemic risk is often linked to clearly quantifiable aspects such as liquidity problems, equity devaluations, and a surge in credit risk (see, for instance, Acharya, 2010). Seemingly less quantifiable aspects, such as operational risks, are not often taken into direct account. Behavioral aspects can manifest themselves in operational risk forms, such as compliance risk or reputational risk (though the latter falls outside of the BCBS definition of operational risk). The Group of Thirty, in its 2015 banking conduct report, ${ }^{132}$ stressed that "poor cultural foundations and significant cultural failures were major drivers of the recent financial crisis," highlighting the link between systemic events at firm-specific cultural and behavioral aspects, not often exacerbated by lacking corporate governance. ${ }^{133}$

Systemic supervision tools could include behavioral aspects, via financial sector governance arrangements. For instance, when conducting stress tests of commercial banks, boardroom dynamics and corporate culture could be included. What happens to decision-making among the board members when a bank gets hit by a rogue trader, having amassed significant losses? Part of this might already be tackled by many banks' business continuity plans, but those only deal with operational aspects (backup IT systems, information sharing protocols, and so on) — not with the behavioral effects such stress events might have on key decisionmakers.

Proportionality in linking behavioral aspects to systemic risk is required. In cases where a country is undergoing an elevated level of systemic stress, for instance, when its single, systemic bank is facing solvency issues, behavioral aspects related to that single bank would play a larger role. This would be in line with the IMF's Financial Sector Assessment

\footnotetext{
${ }^{131}$ McBarnet (2006).

132 Group of Thirty (2015).

133 "Lack of trust and confidence in the banking sector creates material costs to society. Fixing culture in banking is now a public trust — as well as an economic_imperative"; ibid.
} 
Handbook: ${ }^{134}$ supervisory approaches differ depending on the structure and state of the financial system, and the level of systemic stress.

\section{Role of Central Banks: Monetary Policy Committees and Communication}

Finally, behavioral aspects are relevant to central banks themselves. Though in many cases nowadays central banks and financial supervisors are integrated into one organization, the preceding paragraphs mostly relate to the financial stability objectives of central banks, and within that objective, the function of microprudential supervision. Other objectives and functions of central banks would similarly stand to gain from behavioral insights.

It should be noted that the application of behavioral elements to central banking is still in a nascent stage, more than for supervisors. This is understandable, given that those agencies are at the forefront of dealing with the behavior of supervised entities. Nevertheless, central banks and their policymakers stand to gain significantly as well.

This relates in particular to monetary policy, as also noted earlier ("Research"). Masciandaro (2014) highlights the relevance of loss aversion, reciprocity norms, and overconfidence for monetary policy, and considerations based on the relationship between unemployment and inflation, and savings/consumption behavior. He also stresses (Masciandaro, 2016) stresses that monetary policy decision-making is subject to several biases, including loss aversion, which "can explain monetary policy inertia in setting interest rates" by central banks. He describes how loss aversion applied to monetary policy decision-making can have three effects: (1) a moderation effect (increasing the number of monetary "pigeons"); (2) a hysteresis effect ("doves" and "hawks" smooth their attitudes); and (3) a smoothing effect (the number of "pigeons" stabilizes). ${ }^{135}$ These three effects trigger higher monetary policy inertia, stressing the conclusion that "central bankers are individuals that are subject to the same source of behavioral bias all individuals face."

This has consequences for the area of governance of central banks as well. The challenge becomes how to design or tweak central bank decision-making to such an extent that "it can produce optimal interest alignment between society and central bankers ... Therefore, the analysis of central bank governance must take into account the relevance of behavioral biases." "136 Similarly, Gabaix (2016) links behavioral pitfalls to monetary and fiscal policy. He describes how bounded rationality (see Section I C) can be used to explain "how poorly

\footnotetext{
134 IMF, 2005 (Annex 10.C Financial Sector Governance-Selected Issues).

135 According to Masciandaro (2016), p. 52, in monetary policy jargon, a "dove" is a policymaker who likes to implement active monetary policies, including inflationary ones; a "hawk" is a policymaker who dislikes them; and a "pigeon" falls in the middle.

${ }^{136}$ On the relevance of central bank governance, and links with behavioral aspects; see also Khan (2016a, 2016b, 2017).
} 
agents understand future policy and its impact," given that they are not fully rational, and the "agent is partially myopic to unusual events and does not anticipate the future perfectly." Haldane (2014) refers to the BoE's governance framework, and four features that are similar to monetary and macro-, and microprudential policy, tasked to minimize behavioral risks: (1) goal dependence (that is, the goals of the BoE's policies are set by parliament); (2) instrument independence (that is, the instruments the BoE uses to implement its policies are decided by the BoE itself); (3) committee-based decision-making (which takes decisions away from individuals to the group, and includes external experts, with different voting regimes); and (4) transparency and accountability.

Finally, central bank communication could likely be improved by using behavioral insights. As Blinder ${ }^{137}$ notes: "As it became increasingly clear that managing expectations is a useful part of monetary policy, communication policy rose in stature from a nuisance to a key instrument in the central banker's toolkit." As such, a central bank's communication policyas an important policy instrument (see, for instance, the unconventional monetary policy tool of "forward guidance"138) — would need to be shaped to the extent that it clearly contributes to the price stability objective of the central bank. An additional complication could arise when a central bank has more than one objective, and central bank communication does not merely relate to a monetary policy tool, but also needs to balance overlap with other central bank objectives, such as in realms of financial stability and/or financial integrity.

There is increasing awareness that behavioral elements play a role in monetary policy communication. Former BoE Governor Mervyn King noted that "[r]ational optimizing behavior is ... too demanding, and actual decisions may reflect the use of heuristics."139 Blinder ${ }^{140}$, referring to this quote, notes that "since central bank communication undoubtedly plays a role in shaping beliefs about those heuristics, it also plays a potentially important role in anchoring expectations," and then continues to note that the public has limitations to how much information from the central bank can be digested in an effective manner, while referring to Daniel Kahneman's Maps of Bounded Rationality: Psychology for Behavioral Economics (2003) — stressing the need for thought-through, balanced, and selective communication. There is no doubt that communication, marketing, and advertisement specialists already long apply what central bankers are starting to explore: people are not

\footnotetext{
${ }^{137}$ Blinder (2016), p. 4.

${ }^{138}$ Mark Carney, Governor of the Bank of England, noted that forward guidance requires that the public understands it: "People have much more important things to worry about than price and financial stability... What do citizens think the guidance is? People understand these messages when they are simple and out there and if it affects behaviour" (Financial Times, "Central bankers warn of limits to forward guidance," November 14, 2017).

${ }^{139}$ King (2005).

${ }^{140}$ Blinder (2016), p. 9.
} 
necessarily rationally operating individuals, and are susceptible to the choice of words, medium of information, the specific messengers, and so on - in other words: resonating with the earlier described MINDSPACE framework of behavioral policymaking.

\section{E. A Behavioral Approach for Financial Supervision, Regulation, and Central Banking}

Summarizing, behavioral elements can — and should — be consciously used in financial regulation and supervision, and other functions of central banks stand to gain from this as well. See Table 3 for an overview of recommendations in the areas of financial supervision and regulation, financial stability, monetary policy, and research, as well as the internal organization of central banks/supervisors, and regulators themselves. These recommendations relate to drafting, application, and enforcement of rules. Supervisors send out formal letters, and start investigations based on the assumption that the recipients will comply, because they have to. Supervisors and regulators try to appeal to the sense of compliance with legal norms, and, in a lot of cases in financial supervision and regulation, compliance with market norms as well (it makes economic sense to comply, otherwise, one might end up with a large liability on the balance sheet). But, any such use of behavioral elements needs to be done consciously by the relevant authority in the five following areas, to maximize its effects and mitigate its potential risks:

(1) In research, central banks and supervisors/regulators should allow for more experimentbased research. This would address effects of behavioral elements on the different policy areas that the organization(s) is/are involved with. Research, as for instance in the BoE's "One Bank Research Agenda," that tries to add to existing tools, makes existing practices more effective, and uses expertise throughout the central bank, as well as from external researchers (for instance, in cooperation with universities).

(2) Financial regulation will benefit from the application of behavioral policy frameworks. Examples of such frameworks are MINDSPACE and EAST. Key is that the central bank/supervisor tries to link into existing behavioral policy frameworks. This likely will be in cooperation with other authorities that might have already experimented with behavioral rule-making, such as tax services, public health agencies, market conduct, and competition authorities, and other public agencies abroad. Corporate governance rules and regulations for financial institutions offer an opportunity for including behavioral insights. Areas relating to board composition and assessments, remuneration policies, and internal controls (including risk management in particular) already deal with identifying, mitigating, and monitoring effects of individual behavior, and therefore could easily be expanded. A BIT, or other dedicated unit, can help behavioral expertise permeate throughout central banks and supervisors/regulators and into the different policymaking areas. 
(3) Financial supervision, including enforcement, stands to gain from behavioral supervision. This would be based on the governance aspects listed above, as well as the help of a BIT in assisting on- and offsite supervisors with tailor-made behavioral interventions.

(4) Financial stability can be improved if the systemic nature of behavioral elements is taken properly into account. The most likely route to do so would be to incorporate behavioral elements into financial system governance, for instance, via moral hazard risk, as well as via the governance arrangements of systemically important financial institutions (the assessment of which would be based on behaviorally enhanced microprudential supervision, as mentioned earlier).

(5) Last, but certainly not least, central bank decision-making could benefit from behavioral insights applied to committee-based decision-making (in particular, monetary policy committees), as well as in the rapidly developing area of central bank communication.

These recommendations require moving beyond the perspective of the utility-maximizing individual. Whether supervision and regulation are based on seeing people as rational egoists, strong reciprocators, or as stewards of a commercial entity, a broader theory of human behavior is needed. ${ }^{141}$ The currently prevailing economic theories and subsequent policies are not effective enough, given their "crowding out norms of trust and reciprocity, by crowding out the knowledge of local circumstances, by crowding out the discussion of ethical issues with others who are affected, and by crowding out the experimentation needed to design effective institutions. Crowding out reciprocity, cooperation, and citizenship is a waste of human and material resources and presents a serious challenge to the sustainability of democratic institutions over time." 142

Importantly, means to measure effectiveness of behaviorally inspired regulatory and supervisory measures are needed as well. Though measures relating to behavioral aspects might be difficult to quantify in general, there is a need for policymakers, regulators, and supervisors to try to do so, and ensure accountability. The examples provided from the UK BIT are cases in point: directly measurable effects in terms of tax returns, compliance with administrative fines, and the level of insurance are several of the options that policymakers in the financial sector could examine.

\footnotetext{
${ }^{141}$ Gintis (2005), p. 254.

142 Ibid., p. 270.
} 


\section{CONCLuSion}

This paper describes how behavioral elements are relevant for financial supervision, regulation, and central banking. It focuses on (1) behavioral effects of norms (social, legal, and market); (2) behavior of others (internalization, identification, and compliance); and (3) psychological biases.

Central banks, financial supervisors, and regulators have not yet realized the full potential that these behavioral elements hold for their public policy areas, nor have they similarly realized the potential risks of not taking these elements on board. To do so, they need to devise approaches that include aspects relating to individual and group behavior, and incorporate what can be learned from other social sciences into new laws, policies, and interventions.

Experimenting with this approach is a straightforward way to start, for instance, by carefully setting up behavioral supervision - including on the systemic and financial stability levelsand drafting guidance for staff working on regulations and staff conducting supervisory interventions. Behavioral insight teams and selected governmental teams set up elsewhere in the world offer concrete examples of how behavioral expertise can be integrated in a lowkey, low-cost manner within any organization.

For board members of financial entities, this means they need to be more aware of the behavior they display both inside and outside the boardroom.

Similarly, central banks, financial supervisors, and regulators themselves need to consider how behavioral elements affect their own decision-making (for instance, on monetary policy), communication, and risk management.

Further research should be conducted especially in the areas of (1) incorporating behavioral expertise into the selection and application of supervisory interventions; (2) examining the behavioral impact of supervision itself; and (3) the links between behavioral elements and systemic risk. 


\section{REFERENCES}

Acemogly, D., M. Jackson, 2015, "Social Norms and the Enforcement of Laws.” Draft, January.

Akerlof, G.A., and R.E. Kranton, 2011, Identity Economics: How Our Identities Shape Our Work, Wages, and Well-Being. Princeton: Princeton University Press.

Ali, P., I. Ramsay, and C. Read, 2014, "Behavioural Law and Economics: Regulatory Reform of Consumer Credit and Consumer Financial Services," SSRN.com.

Appelbaum, R.P., D. Carr, M. Duneir, and others, 2009, "Conformity, Deviance, and Crime," Introduction to Sociology. New York: W.W. Norton \& Company, Inc.

Ariely, D., and G. Loewenstein, 2005, "Heat of the Moment: The Effect of Sexual Arousal on Sexual Decision Making."

Ariely, D., 2010, Predictably Irrational: The Hidden Forces That Shape Our Decisions. Ayres, I., and J. Braithwaite, 1992, Responsive Regulation-Transcending the Deregulation Debate, London: Oxford University Press.

Bainbridge, S., "Dodd-Frank: Quack Federal Corporate Governance Round II," 95 Minnesota Law Review 1779, 2011.

Bank of England, 2015, “One Bank Research Agenda,” Discussion Paper.

Barro, R., and R. McCleary, 2003, "Religion and economic growth," American Sociological Review, 68 (2003), pp. 760-81.

Bazerman, M.H., and A.E. Tenbrunsel, 2011, Blind Spots: Why We Fail to Do What's Right and What to Do about It (summary on www.hbs.edu, "Blind Spots: We're Not as Ethical as We Think," April 20, 2011).

Behavioural Insights Team, The, 2014, "EAST: Easy, Attractive, Social, Timely: Four Simple Ways to Apply Behavioural Insights." London: Behavioural Insights Team Ltd. Behavioural Insights Team, The, 2015, “Update Report 2013-2015.” London:

Behavioural Insights Team Ltd.

Bicchieri, C., and E. Xiao, 2009, "Do the Right Thing: But Only if Others Do So," Journal of Behavioral Decision Making, 22.

Blinder, A.S., M. Ehrmann, M. Fratzscher, and others, 2008, "Central Bank Communication and Monetary Policy: A Survey of Theory and Evidence," NBER Working Paper No. 13932.

Boutellier, H., 2010, De improvisatiemaatschappij: over de sociale ordening van een onbegrensde wereld.

Braithwaite, J., 1984, Corporate Crime in the pharmaceutical industry.

Braithwaite, J., V. Braithwaite, 1995, "The Politics of Legalism: Rules Versus Standards in Nursing-Home Regulation," Social \& Legal Studies 4: 307+.

Brazier, A., R. Harrison, M. King, and T. Yates, 2006, "The danger of inflating expectations of macroeconomic stability: heuristic switching in an overlapping generations monetary model," Bank of England Working Paper No. 303. 
Center for Progressive Reform, 2010, Regulatory Blowout: How Regulatory Failures Made the BP Disaster Possible, and How the System Can Be Fixed to Avoid a Recurrence.

Clark, A., and J. Treanor, "Greenspan: I was wrong about the economy. Sort of," The Guardian, October 24, 2008.

Damasio, A.R., 1996, Descartes' Error.

Darwin, C., 1871, The Descent of Man.

Davidson, B.I., and D.E. Stevens, 2010, "Can a Code of Ethics Improve Manager

Behavior and Investor Confidence? An Experimental Study."

De Nederlandsche Bank, 2009, The Seven Elements of an Ethical Culture: Strategy and approach to behavior and culture at financial institutions 2010-2014. Amsterdam: De Nederlandsche Bank NV.

De Nederlandsche Bank, 2013, Leading by Example-Conduct in the Board Rooms of Financial Institutions Amsterdam: De Nederlandsche Bank NV.

De Vries, F., 2013, "How Can Principles-Based Regulation Contribute to Good Supervision?" Supervision in the 21st Century. Berlin: Springer Verlag AG.

Dennett, D., 1991, Consciousness Explained.

Dijkstra, K., 2012, Intuition versus Deliberation: The Role of Information Processing in Judgment and Decision Making, $\mathrm{PhD}$ dissertation.

Ehrmann, M., and D. Jansen, 2012, "The pitch rather than the pit: investor inattention during FIFA World Cup matches," European Central Bank Working Paper No. 1424. Erhard, W.H., M.C. Jensen, and S. Zaffron, 2008, "Integrity: A positive model that incorporates the normative phenomena of morality, ethics and legality," Harvard NOM Research Paper No. 06-11.

Esgate, A., and D. Groome, 2005, An Introduction to Applied Cognitive Psychology. Psychology Press.

European Banking Authority, 2011, Guidelines on Internal Governance, No. 44.

European Central Bank, 2014, Guide to Banking Supervision.

European Commission, 2013, "Applying Behavioral Sciences to EU Policy-making,"

JRC Scientific and Policy Reports, EUR 26033.

European Union Capital Requirements Directive IV, 2013, 575/2013.

Fehr, E., and A. Falk, 2002, "Psychological Foundations of Incentives," Institute for the Study of Labor IZA, Working Paper No. 507.

Fehr, E., and S. Gächter, 2000, "Do Incentive Contracts Crowd Out Voluntary

Cooperation?" USC Center for Law, Economics and Organization, Research Paper No. C01-3.

Feldman, Y., 2017, “Curbing the Corruption of 'Good People': Integrating Legal and Behavioral Perspectives on Ethicality," Behavioral Science and Policy (forthcoming), SSRN.com.

Frey, B., and R. Jegen, 2002, "Motivation Crowding Theory: a Survey of Empirical Evidence," CESifo, Working Paper No. 245. 
Fruehwald, E.S., 2010, “An Introduction to Behavioral Biology for Legal Scholars,” SSRN.

FSA Policy Paper, 2007, "Principles-based regulation: Focusing on the outcomes that matter."

Gabaix, X., 2016, “A Behavioral New Keynesian Model,” CEPR Discussion Paper, DP11729.

Gintis, H. and others, editors, 2005, Moral Sentiments and Material Interests.

Green, S., 2014, "Anybody who thinks he can pull up drawbridges is kidding himself," interview by Jürgen Frank in The Focus, Vol. XIV/1.

Group of Thirty, 2015, Banking Conduct and Culture: a Call for Sustained and

Comprehensive Reform.

Guiso, L., P. Sapienza, and L. Zingales, 2003, "People's opium? Religion and economic attitudes." Journal of Monetary Economics, 50 (2003), pp. 225-82.

Haldane, A.G., 2014, "Central bank psychology," speech at the Royal Society of Medicine conference "Leadership: stress and hubris conference," London, November 17, 2014.

Hauser, M.D., 2006, Moral minds-How nature designed our universal sense of right and wrong.

Hertz, N., 2011, "How to use experts - and when not to," TED talk (www.ted.com). Hilary, G., and K.W. Hui, 2009, "Does Religion Matter in Corporate Decision Making in America," Journal of Financial Economics, Vol. 93, No. 3, pp. 455-73.

Ho, G., and P. Mauro, 2015, "Prognosis: Rosy," Finance and Development, Vol. 52, No. 1, p.40-43.

Iannaccone, L., 1998, "Introduction to the economics of religion," Journal of Economic Literature, 36 (1998), pp. 1465-96.

Institute of International Finance, 2013, "Promoting Sound Risk Culture: lessons learned, challenges remaining and areas for further consideration," IIF Issues Paper.

International Monetary Fund, 2005, Financial Sector Assessments: A Handbook.

Jansen, R., 2011, Wellink aan het woord.

Jensen, M.C., and W.H. Meckling, 1976, "Theory of the Firm: Managerial Behavior, Agency Costs and Ownership Structure," Journal of Financial Economics, V.3, No.4, pp. 305-60.

Jones, D., 2014, "Why Behavioral Economics Isn't Better, and How it Could Be," Version of October 12, 2014, SSRN.com, forthcoming in Teitelbaum, J.C., and K. Zeiler, editors, 2015, Research Handbook on Behavioral Law and Economics.

Kaptein, M., R. Rozekrans, and R. De Groot, 2005, "Integriteitklimaat als auditobject," $M A B$, pp. 466-74.

Kelman, H.C., 1958, "Compliance, identification, and internalization-three processes of attitude change," The Journal of Conflict Resolution, Volume II, No. 1, pp. 51-60. Khan, A., 2016a, "Central Bank Governance and the Role of Nonfinancial Risk Management," IMF Working Paper 16/37.

Khan, A., 2016b, "Set the Tone at the Top," Finance \& Development, Vol. 53, No. 4. 
Khan, A., 2017, "Central Bank Legal Frameworks in the Aftermath of the Global Financial Crisis," IMF Working Paper (forthcoming).

King, M., 2005, "Monetary Policy: Practice Ahead of Theory," Mais Lecture.

La Porta, R., F. Lopez-de-Silanes, A. Shleifer, and R. Vishny, 2009, “The quality of government," Journal of Law, Economics and Organization, 15 (1999), pp. 222-79.

Lawrence, P.R., and N. Nohria, 2002, Driven: How Human Nature Shapes Our Choices. Lombardelli, C., J. Proudman, and J. Talbot, 2002, "Committees versus individuals: an experimental analysis of monetary policy decision-making," Bank of England Working Paper No. 165.

Luckerath-Rovers, M., 2011, "Mores Leren: Soft Controls in Corporate Governance," inaugural speech, Nyenrode Business University.

Masciandaro, D., and F. Favaretto, 2014, "Behavioral Economics and Monetary Policy," BAFFI CAREFIN Centre Research Paper Series, No. 2015-1.

Masciandaro, D., F. and Favaretto, 2016, "Doves, hawks, and pigeons: Behavioral monetary policy and interest rate inertia," Journal of Financial Stability, 27 (2016) 5058.

McBarnet, D., 2006, “After Enron: Will 'whiter than white collar crime' still wash?” The British Journal of Criminology, Vol. 46, No. 6, November 1, 2006, pp. 1091-109. McKinsey Quarterly, 2011, Governance since the economic crisis: McKinsey Global Survey results.

Mertens, F.J.H., 2012, “Cultuur van organisaties als aangrijpingspunt voor toezicht," Tijdschrift voor Toezicht, Vol. 3.

Miller, F.P., A.F. Vandome, and J. McBrewster, 2009, Confirmation Bias. VDM Publishing.

Nesterak, E., 2014, "Head of White House 'Nudge Unit' Maya Shankar Speaks about Newly Formed Social and Behavioral Sciences Team," www.thepsychreport.com, July $13,2014$.

OECD, 2009, The Corporate Governance Lessons from the Financial Crisis.

Prendergast, C., 1999, “The Provision of Incentives in Firms," Journal of Economic Literature, XXXVII, 7-63.

Promberger, M., T.M. Marteau, 2013, "When Do Financial Incentives Reduce Intrinsic Motivation? Comparing Behaviors Studied in Psychological and Economic Literatures," Health Psychology. September 2013; 32(9): 950-57.

Raz, J., 1983, The Authority of Law.

Schwartz, S.H., 1977, "Normative influences on altruism," Advances in experimental social psychology, No. 10, pp. 221-79.

Shavell, S., 2010, "When is it socially desirable for an individual to comply with the law?” Discussion Paper No. 682, Harvard Law School.

Shefrin, H., 2002, Beyond Greed and Fear-Understanding Behavioral Finance and the Psychology of Investing.

Shefrin, H., 2011, “BP's Failure to Debias: Underscoring the Importance of Behavioral Corporate Finance," PRMIA webinar 
(http://www.prmia.org/Weblogs/General/PRMIA docs/BP'sFailuretoDebiasHershShefrin.pdf).

Shiller, R.J., 2012, Finance and the Good Society.

Smith, A., 1776, The Wealth of Nations.

Smits, J.M., 2003, Monografieën Nieuw BW: Bronnen van verbintenissen, A2.

Sparrow, M.K., 2000, The Regulatory Craft: Controlling Risks, Solving Problems, and Managing Compliance.

Sparrow, M.K., 2009, Mapping the Regulatory Landscape, Presentation at Harvard University, October 21, 2009.

Stout, L., 2011, Cultivating Conscience, How Good Laws Make Good People.

Stulz, R., and R. Williamson, 2003, "Culture, openness, and finance," Journal of Financial Economics, 70 (2003), pp. 313-49.

Sunstein, C.R., 2014, "The Ethics of Nudging," Very Preliminary Draft 11/20/14, SSRN.com.

Sunstein, C.R., 2015, "Which Nudges Do People Like? A National Survey," Preliminary Draft 6/22/15, SSRN.com

Swaab, D.F., 2010, Wij zijn ons brein—Van Baarmoeder tot Alzheimer. Amsterdam:

Atlas Contact.

Taylor, T., 2014, "Economics and Morality," Finance and Development, Vol. 51, No. 2, pp. 34-38.

Tversky, A., and D. Kahneman, 1974, "Judgment under Uncertainty: Heuristics and Biases," Science, Vol. 185, pp. 1124-31.

Van Rooij, M., A. Lusardi, and R. Alessie, 2012, "Financial literacy, retirement planning, and household wealth," Economic Journal, 122 (May), 449-78.

Veltrop, D.B., and J. de Haan, 2014, "Regulatory Capture of Financial Supervisors: A Social Identity Perspective," DNB Working Paper (forthcoming).

Whetten, D.A., 1989, "What Constitutes a Theoretical Contribution," Academy of Management Review, Vol. 14, No. 4, 490-95.

Williams, M., 1999, Science and Social Science: An Introduction.

Winter, J.W., 2010, “Geen regels maar best practices, in Willems' wegen: Opstellen aangeboden aan prof. mr. J.H.M. Willems."

Winter, J.W., 2011, "Corporate Governance Going Astray_Executive Remuneration Built to Fail," Duisenberg School of Finance Policy Paper No. 5.

World Bank, 2015, Mind, Society, and Behavior, World Development Report

Washington: The World Bank 